\title{
UV Light Combined with Nitrate Remove Bisphenol A: Kinetics, Transformation Pathways, and Acute Toxicity Assessment
}

\section{Zhiquan Li}

Shandong Jianzhu University

Congwei Luo (D luocongwei2009@163.com )

Shandong Jianzhu University

Fengxun Tan

Shandong Jianzhu University

Daoji Wu

Shandong Jianzhu University

Shishun Wang

Shandong Jianzhu University

Xiaoxiang Cheng

Shandong Jianzhu University

Fumiao Zhang

Shandong Jianzhu University

Mingli Li

Shandong Jianzhu University

Qiao Ma

Shandong University

\section{Research Article}

Keywords: Bisphenol A, Nitrate, Photodegradation, Kinetics, Degradation pathway

Posted Date: August 13th, 2021

DOl: https://doi.org/10.21203/rs.3.rs-509991/v1

License: (c) (i) This work is licensed under a Creative Commons Attribution 4.0 International License.

Read Full License 


\section{UV light combined with nitrate remove bisphenol A: kinetics, transformation pathways, and acute toxicity assessment} University, Jinan, 250101, P. R. China.

${ }^{\mathrm{b}}$ Resources and Environment Innovation Institute, Shandong Jianzhu

University, Jinan, 250101, P. R. China.

${ }^{\mathrm{c}}$ National Engineering Lab of Coal-Fired Pollution Emission Reduction, School

of Energy and Power Engineering, Shandong University, Jinan 250061, P. R. China

2

(4)

*Corresponding authors contact details:

3 Doc. Congwei Luo, Phone: 86-531-86367291, email: luocongwei2009@163.com 4 
As a powerful endocrine disruptor, bisphenol A (BPA) is a serious threat to human health. In this study, low-pressure UV lamp (LP-UV) photolysis nitrate was used to degrade BPA in different aqueous solutions. Results showed that BPA could be decomposed efficiently in the $\mathrm{UV} /$ nitrate process. $\cdot$ OH played a significant role in the $\mathrm{UV} /$ nitrate process, and the steady-state concentration of $\cdot \mathrm{OH}\left([\cdot \mathrm{OH}]_{\mathrm{ss}}\right)$ was calculated to be $5.26 \times 10^{-15} \mathrm{M}$ under control conditions. Moreover, the contributions of UV irradiation $(4.1 \%), \cdot \mathrm{OH}(52.7 \%)$, and reactive nitrogen species (43.2\%) were obtained. The observed rate constant of BPA degradation $\left(k_{\mathrm{obs}}\right)$ increased with nitrate concentration since more activity species were generated in high nitrate concentration. BPA degradation rate significantly accelerated as the $\mathrm{pH}$ value rose, it was ascribed to the increase of the molar absorption coefficient and the portion of ionic BPA. However, $k_{\text {obs }}$ declined with increasing BPA concentration result from the inner filter effect and the competition of more generated intermediate products. The increasing decomposition of BPA with the addition of $\mathrm{HCO}_{3}{ }^{-} / \mathrm{CO}_{3}{ }^{2-}(0 \sim 10 \mathrm{mM})$, which could be explained as $\mathrm{HCO}_{3}{ }^{-} / \mathrm{CO}_{3}{ }^{2-}$ scavenged $\cdot \mathrm{OH}$ resulting in the accumulation of $\cdot \mathrm{NO}_{2}$. The

41 effect of $\mathrm{Cl}^{-}(0 \sim 20 \mathrm{mM})$ can be ignored, which suggested reactive chlorine radicals degraded BPA effectively. The $k_{\text {obs }}$ reduced acutely when NOM $(0 \sim 5 \mathrm{mg}-\mathrm{C} / \mathrm{L})$ existed in the solution, this could be ascribed to the dual role of NOM inner filter effect and reactive radicals scavenging effect. Further, several degradation products were detected and possible transformation pathways were put forward. Remarkably, the acute toxicity 
of BPA was slightly enhanced then decayed in the UV/nitrate process.

Keywords: Bisphenol A; Nitrate; Photodegradation; Kinetics; Degradation pathway

\section{Introduction}

Various man-made chemicals, such as pesticides, flame retardants, plastic additives, cosmetics, are widely distributed in this century (Burman et al. 2020). Endocrine

51 disruptors (EDCs) may be released from these various chemicals, affecting the

52 endocrine (hormonal) system of wild animals, even leading to human diseases like

53 diabetes mellitus, obesity, autoimmune diseases, and cancer (Bergman et al. 2013;

54 Diamanti-Kandarakis et al. 2009). Bisphenol A(BPA), as an important endocrine

55 disruptor possessed estrogenic activity, is a high-volume chemical and a widespread

56 plasticizer (Gore et al. 2019; Kahn et al. 2020). Food and drinking water could be

57 contaminated through migration after BPA is released from chemical products

58 (Newbold et al. 2007). Although the BPA concentration detected in surface water and

59 sediments are low (i.e., nd 30ng/L in surface water, 5.3 6.1 ng/g dry weight in

60 sediments, respectively), a great danger to biological health can be presented by it (Hu

61 et al. 2019; Welshons et al. 2006).

62 For this reason, the European Commission updated the new regulation on BPA in

63 food packaging in 2018. The Specific Migration Limit (SML) of bisphenol A was set

64 as $0.05 \mathrm{mg}$ per kilogram of eatables (Vilarinho et al. 2019). Besides, the government of

65 Canada limited the concentration of BPA released in wastewater to no more than 1750 
ng/L in 2012 and 2013 (Gewurtz et al. 2021). Moreover, the United States, France, and other countries have forbidden the usage of BPA in infant feeding bottles and toys for a long time, because infants are more sensitive to its estrogenic activity (Jeong et al. 2020). Despite the above measures, the global volume of BPA usage is estimated to achieve 10.6 million tons by 2022 (de Freitas et al. 2017).

71 Conventional methods of water purification (e.g., coagulation, filtration, adsorption, and biodegradation) are insufficient for completely degrade EDCs, especially BPA made up of strong bonds hence (Gmurek et al. 2017; Luo et al. 2014). However, many advanced oxidation processes (AOPs) especially the UV-based AOPs can be selectively applied to degrade BPA, such as UV combined with $\mathrm{H}_{2} \mathrm{O}_{2}$, chlorine, persulfate (PS), or peroxymonosulfate (PMS) (Chaves et al. 2020; Rodríguez-Chueca et al. 2019; Sharma et al. 2015). Chaves et al. (2020) found that the BPA decomposition rate reached 55\% in UVA/ $\mathrm{H}_{2} \mathrm{O}_{2}$ process $\left(88 \mu \mathrm{M} \mathrm{H}_{2} \mathrm{O}_{2}\right)$ for $120 \mathrm{~min}$. Sharma et al. (2016) have pointed out that the BPA degradation increased in UV-C/SPS oxidation system as a result of the BPA molecules attacked by the $\mathrm{SO}_{4}{ }^{-}$radicals. Over recent years, the UV/nitrate system

81 has received growing attention because nitrate $\left(\mathrm{NO}_{3}{ }^{-}\right)$is a naturally occurring ion 82 involved in the nitrogen cycle in the environment and it can effectively decompose 83 EDCs (e.g., estrone, and 17 $\alpha$-ethynylestradiol) (Huang et al. 2018; Sato et al. 2018).

84 With further studies, reactive oxygen species (ROS) and reactive nitrogen species (RNS) 85 are generated in the UV/nitrate process, as shown in Eqs. (1) (6) (Goldstein \&Rabani 86 2007; Mack \&Bolton 1999). 
$\mathrm{NO}_{3}^{-} \stackrel{\mathrm{hv}}{\rightarrow} \cdot \mathrm{NO}_{2}+\mathrm{O}^{-}$

$88 \quad \mathrm{NO}_{3}^{-} \stackrel{\text { hv }}{\rightarrow} \mathrm{NO}_{2}^{-}+\mathrm{O}\left({ }^{3} \mathrm{P}\right)$

$\mathrm{O}^{\cdot-}+\mathrm{H}_{2} \mathrm{O} \rightarrow \cdot \mathrm{OH}+\mathrm{OH}^{-}$

$90 \quad \mathrm{NO}_{2}^{-} \stackrel{\mathrm{hv}}{\rightarrow} \cdot \mathrm{ON}+\mathrm{O}^{-}$

$91 \quad \mathrm{NO}_{3}^{-}+\mathrm{H}^{+} \stackrel{\mathrm{hv}}{\rightarrow} \mathrm{ONOO}^{-}+\mathrm{H}^{+} \leftrightarrow \mathrm{ONOOH}$

$\mathrm{ONOOH} \leftrightarrow \cdot \mathrm{NO}_{2}+\cdot \mathrm{OH}$

93 Among the reactive species, hydroxyl radical $\left(\mathrm{E}_{0}=2.73 \mathrm{~V}\right.$ vs NHE) shows strong nonselective, which can destroy BPA molecular structure at a fairly high second-order rate constant (Luo et al. 2015). Some ROS (e.g., $\mathrm{O}^{\circ}, \mathrm{O}_{2}{ }^{\circ}$, and $\left.\mathrm{O}^{3} \mathrm{P}\right)$ ) are not be taken into account in the UV/nitrate system because of their relatively low concentration and weak oxidability (Huang et al. 2018). RNS, such as $\cdot \mathrm{NO}_{2}$ and $\cdot \mathrm{NO}$, have relatively weaker oxidation ability $\left(\mathrm{E}_{0}=1.03 \mathrm{~V}\right.$ and $\mathrm{E}_{0}=0.39 \mathrm{~V}$, respectively) (Huang et al. 2018). However, these weak oxidizing radicals can selectively react with some electron-donating moieties compounds via electrophilic substitution (Vione et al. 2004). Overall, it could

101 be predicted that BPA should be degraded effectively in the UV/nitrate process.

102 However, the degradation kinetics, transformation pathways, and acute toxicity 103 assessment of BPA degradation by the UV/nitrate have not been investigated.

104 Therefore, this work aims to achieve the following objectives: (i) to assess the 105 proportions of direct UV, RNS, and $\cdot \mathrm{OH}$ to BPA decomposition in UV/nitrate system, 106 (ii) to analyze the effect of $\mathrm{NO}_{3}{ }^{-}$concentration, initial $\mathrm{BPA}$ dosage, $\mathrm{pH}$ values, common 107 anions (including bicarbonate/carbonate $\left(\mathrm{HCO}_{3}{ }^{-} / \mathrm{CO}_{3}{ }^{2-}\right)$ and chloride ions $\left(\mathrm{Cl}^{-}\right)$), and 
natural organic matter (NOM) on BPA decomposition in the UV/nitrate process, (iii) to

109 analyze intermediate products and explore the possible transformation pathways, (iv)

110 to assess the acute toxicity and evaluate application significant of UV/nitrate system in

111 actual waters.

\section{2. Materials and methods}

1132.1 Chemicals

114 Bisphenol A (99\%), nitrobenzene (NB) (99\%), sodium nitrate (99\%), and perchloric 115 acid were from Aladdin. Sodium chloride, sodium bicarbonate, disodium hydrogen 116 phosphate, sodium dihydrogen phosphate, sodium hydroxide, and acetic acid (HPLC 117 grade) were from Sinopharm Chemical Reagent Company. Natural organic matter 118 (NOM) was from the International Humic Substances Society. Methanol (HPLC grade) 119 and was from Tedia Company. Groundwater and surface water were obtained from 120 Baotu Spring and Xiaoqing River in Jinan, China. Drinking water was taken from the 121 municipal tap and left for two days before use. De-ionized water was obtained from the 122 Milli-Q Biocel water system.

\subsection{Analytical methods}

124 The concentrations of BPA, NB were detected using high-performance liquid 125 chromatography (HPLC, Waters 2695) reported in the previous study (Gao et al. 2020b).

126 The constituents of the mobile phase were methanol and $0.1 \%$ acetic acid (70:30 for 127 BPA, NB), with a flow rate of $1.0 \mathrm{~mL} \mathrm{~min}^{-1}$. The sample injection volume of BPA and $128 \mathrm{NB}$ were $50 \mu \mathrm{L}$ and $100 \mu \mathrm{L}$, respectively. UV absorption of BPA and NB were 
monitored at $278 \mathrm{~nm}$, and $262 \mathrm{~nm}$, respectively. The concentrations of $\mathrm{NO}_{3}{ }^{-}$and $\mathrm{NO}_{2}{ }^{-}$

130 of actual waters were determined by a double beam ultraviolet-visible

131 spectrophotometer (Metash, UV9000). The concentration of NOM and total organic

132 carbon (TOC) was obtained using a Shimadzu TOC analyzer (TOC-L), and the pH

133 values were detected by a $\mathrm{pH}$ meter (Sartorius, PB-10). A Waters alliance 2695

$134 \mathrm{XELC} / \mathrm{MS} / \mathrm{MS}$ (Waters, Watford, UK) and Zobax SB-C18 $(5 \mu \mathrm{m}, 4.6 \mathrm{~mm} \times 250 \mathrm{~mm}$,

135 Agilent, USA) were combined as the LC/MS/MS system to detect intermediate

136 products. Detailed LC-MS/MS information is elucidated in Text S1.

$137 \quad 2.3$ Experimental methods

138 The photochemical experiment was conducted using four $10 \mathrm{~W}$ low-pressure Hg UV

139 lamps (peak wavelength output at $254 \mathrm{~nm}$, Heraeus, GPH212T5L/4) in a closed box.

140 The UV light intensity was $0.172 \mathrm{~mW} \cdot \mathrm{cm}^{-2}$ after preheating for an hour. In order to

141 facilitate the detection, the control experiment conditions were set as $30 \mu \mathrm{M}$ BPA and

$14230 \mathrm{mM}$ nitrate. All experiments were conducted in de-ionized water under a controlled

143 temperature $\left(25 \pm 1^{\circ} \mathrm{C}\right)$. The buffer used was $5 \mathrm{mM}$ phosphate and $\mathrm{pH}$ adjusted by 0.1

$144 \mathrm{M} \mathrm{NaOH}$ or $\mathrm{HClO}_{4}$. The samples were withdrawn at predetermined time intervals.

145 Based on the methods reported by Wu et al. (2016b), toxicity assessment was carried

146 out by using Vibrio fischeri strains. Detailed methods of the acute toxicity test are

147 shown in Text S1.

148 2.4 Calculation of contributions of $\mathrm{UV}, \cdot \mathrm{OH}$, and RNS

149 As illustrated in Fig. 1, the $\mathrm{NO}_{3}{ }^{-}$concentration did not decrease significantly after 
the 3600 s process, and a very small amount of nitrite produced was detected. This

151 result was the same as that of Huang et al, so the steady-state assumption can be used

152 to calculate the concentration of radicals in this experiment (Huang et al. 2018). As a

153 result of negligible reacting between nitrobenzene (NB) and RNS, NB (50 $\mu \mathrm{M}, k \cdot \mathrm{OH}, \mathrm{NB}$

$154=3.9 \times 10^{9} \mathrm{M}^{-1} \mathrm{~s}^{-1}$ ) was selected to calculate the steady-state concentration of $\cdot \mathrm{OH}$

$155\left([\cdot \mathrm{OH}]_{\mathrm{ss}}\right)$ in the UV/nitrate systems (Buxton et al. 1988, Huang et al. 2018). The

156 calculation formula of $[\cdot \mathrm{OH}]_{\mathrm{ss}}$ (Eq. (8)) can be obtained by transforming Eq. (7). The

$157[\cdot \mathrm{OH}]_{\mathrm{ss}}$ at different concentrations of $\mathrm{NO}_{3}{ }^{-}$(i.e., $10 \mathrm{mM}, 20 \mathrm{mM}, 30 \mathrm{mM}$, and $50 \mathrm{mM}$ )

158 are shown in Table S1.

$\left.159-\frac{\mathrm{d}[\mathrm{NB}]}{\mathrm{dt}}=k_{\mathrm{UV}, \mathrm{NB}}[\mathrm{NB}]+k \cdot \mathrm{OH}, \mathrm{NB} \cdot \cdot \mathrm{OH}\right]_{\mathrm{ss}}[\mathrm{NB}]=k_{\mathrm{obs}, \mathrm{NB}}[\mathrm{NB}]$

$160 \quad[\cdot \mathrm{OH}]_{\mathrm{ss}}=\frac{k_{\mathrm{obs}, \mathrm{NB}-k_{\mathrm{UV}, \mathrm{NB}}}}{k_{\cdot \mathrm{OH}, \mathrm{NB}}}$

161 Similarly, the degradation of BPA can be expressed by Eq. (9).

$162-\frac{\mathrm{d}[\mathrm{BPA}]}{\mathrm{dt}}=k_{\mathrm{UV}, \mathrm{BPA}}[\mathrm{BPA}]+k_{\cdot \mathrm{OH}, \mathrm{BPA}}[\cdot \mathrm{OH}]_{\mathrm{ss}}[\mathrm{BPA}]+k_{\mathrm{RNS}, \mathrm{BPA}}[\mathrm{RNS}][\mathrm{BPA}]$

$163=k_{\text {obs, } \mathrm{BPA}}[\mathrm{BPA}]$

164 Because of the following relationship (Eq. (10)), the contribution ratios of $\mathrm{UV}, \cdot \mathrm{OH}$,

165 and RNS for BPA decomposition in the UV/nitrate process can be calculated,

166 respectively.

$167 \quad \mathrm{R}=\mathrm{R}_{\mathrm{UV}}+\mathrm{R}_{\cdot \mathrm{OH}}+\mathrm{R}_{\mathrm{RNS}}$

168 Where $k_{\mathrm{UV}, \mathrm{NB}}$ and $k_{\mathrm{UV}, \mathrm{BPA}}$ represent apparent rate constant of NB and BPA in the 169 direct UV process, respectively, and $k_{\cdot \mathrm{OH}, \mathrm{NB}}, k_{\mathrm{OH}, \mathrm{BPA}}$, and $k_{\mathrm{RNS}, \mathrm{BPA}}$ are the second170 order rate constants of $\cdot \mathrm{OH}$ with $\mathrm{NB}, \cdot \mathrm{OH}$ with $\mathrm{BPA}$, and RNS with BPA, respectively. 
171 Where $\mathrm{R}_{\mathrm{UV}}, \mathrm{R}_{\mathrm{OH}}$, and $\mathrm{R}_{\mathrm{RNS}}$ are the contributions of $\mathrm{UV}, \cdot \mathrm{OH}, \mathrm{RNS}$ on BPA

172 decomposition. Based on studies of Huang et al, the details of calculations about

173 contributions in the control experiment are shown in Text S2 and Table S2 (Huang et

174 al. 2018; Zhou et al. 2020).

\section{3. Results and discussion}

176 3.1 Contributions of reactive species on BPA decomposition.

177 In the work, BPA degradation efficiencies in direct UV and UV/nitrate processes 178 were quite different. Fig. S1 demonstrates that $30 \mu \mathrm{M}$ BPA was efficiently degraded in 179 the UV/nitrate process while direct UV had a little effect and the degradation of BPA in 180 sole $\mathrm{NO}_{3}{ }^{-}$was negligible. In reality, the root cause of this phenomenon is that $\mathrm{UV}_{254}$

181 irradiation of $\mathrm{NO}_{3}^{-}$generates reactive oxygen radicals (e.g., $\mathrm{OH}, \mathrm{O}^{-}, \mathrm{O}\left({ }^{3} \mathrm{P}\right)$ ) and 182 reactive nitrogen radicals (e.g., $\cdot \mathrm{NO}_{2}, \cdot \mathrm{NO}, \mathrm{ONOO}^{-}$) (Mack \&Bolton 1999). What is 183 more important, the second-order rate constant of $\cdot \mathrm{OH}$ with BPA is $1.02 \times 10^{10} \mathrm{M}^{-1} \mathrm{~s}^{-1}$ 184 and $\cdot \mathrm{OH}$ plays a crucial part in the UV/nitrate process (Rosenfeldt \&Linden 2004).

185 The NB degradation in different dosages of $\mathrm{NO}_{3}{ }^{-}$is shown in Fig. 2. And the 186 calculated $[\cdot \mathrm{OH}]_{\mathrm{ss}}$ in Table $\mathrm{S} 1$ shows the increase of $[\cdot \mathrm{OH}]_{\mathrm{ss}}$ with the concentration of $187 \mathrm{NO}_{3}{ }^{-}$, i.e., $5.64 \times 10^{-16} \mathrm{M}, 1.15 \times 10^{-15} \mathrm{M}, 5.26 \times 10^{-15} \mathrm{M}$, and $7.45 \times 10^{-15} \mathrm{M}$ at $10,20,30$, $18850 \mathrm{mM} \mathrm{NO}_{3}^{-}$, respectively.

189 As demonstrated in Fig. S2, after $3600 \mathrm{~s}$ of irradiation, the removal ratio of BPA in

$190 \mathrm{UV} /$ nitrate control experiment system was 30.39\%. Obviously, RNS played a 191 significant role and $\mathrm{UV}, \cdot \mathrm{OH}$, and RNS accounted for $4.1 \%, 52.7 \%$, and $43.2 \%$ (Fig. 3 ) 
192 of the total removal ratio, respectively. Therefore, although the $[\cdot \mathrm{OH}]_{\mathrm{ss}}$ was low in the 193 control experiment, the contribution of $\cdot \mathrm{OH}$ to BPA was larger than that of RNS can

194 attribute to their superhigh second-order reaction rate constant.

195

\subsection{Effect of $\mathrm{NO}_{3}{ }^{-}$concentration}

The influence of $\mathrm{NO}_{3}{ }^{-}$dosage on the BPA degradation was evaluated. As shown in Fig. 4, the increase of $\mathrm{NO}_{3}{ }^{-}$dosage noteworthily accelerated the degradation of BPA. When the $\mathrm{NO}_{3}{ }^{-}$dosage was less than $30 \mathrm{mM}$, BPA decomposition followed a pseudofirst-order degradation model, indicating the $\mathrm{NO}_{3}{ }^{-}$concentration was directly proportional to the decomposition efficiency of BPA. The present results suggest that increasing $\mathrm{NO}_{3}{ }^{-}$concentration can generate more reactive oxygen species (ROS) and reactive nitrogen species (RNS). A comparable finding was mentioned in the study for atrazine(ATZ) degradation in the $\mathrm{UV}_{255} / \mathrm{NO}_{3}{ }^{-}$process by $\mathrm{Bu}$ et al. (2020), and it reported that when the $\mathrm{NO}_{3}{ }^{-}$dosage increased by 50 folds, the ATZ degradation improved from $15.2 \%$ to $45.8 \%$.

Nevertheless, it is noteworthy that when $\mathrm{NO}_{3}{ }^{-}$concentration increased by $50 \mathrm{mM}$, a downward trend was showed up. For instance, $k_{\text {obs }}$ just increased 3.36 time when $\mathrm{NO}_{3}{ }^{-}$ rose 5 time (i.e., $3.869 \times 10^{-5} \mathrm{~s}^{-1}$ at $10 \mathrm{mM} \mathrm{NO}_{3}^{-} v s .1 .302 \times 10^{-4} \mathrm{~s}^{-1}$ at $50 \mathrm{mM} \mathrm{NO}_{3}^{-}$). It can be explained that excessive concentration of $\mathrm{NO}_{3}{ }^{-}$can inhibit the BPA degradation due to the reaction of $\cdot \mathrm{OH}$ with $\cdot \mathrm{NO}$ and $\mathrm{NO}_{2}^{-}$(see Eqs. (11) (12)) generated in the UV/nitrate process (Buxton et al. 1988; Gonzalez \&Braun 1995).

$$
\cdot \mathrm{OH}+\mathrm{NO}_{2}^{-} \rightarrow \cdot \mathrm{NO}_{2}+\mathrm{OH}^{-}, k=1.0 \times 10^{10} \mathrm{M}^{-1} \mathrm{~s}^{-1}
$$




\section{$214 \quad 3.3$ Effect of the initial BPA concentration}

215 The influence of the initial BPA concentration $(5 \sim 50 \mu \mathrm{M})$ was also examined in the $216 \mathrm{UV} /$ nitrate process. According to the results of Fig. 5, the $k_{\text {obs }}$ decreased from $3.297 \times 10^{-}$

$217{ }^{4}$ to $5.793 \times 10^{-5}$ with the BPA concentration rose from $5 \mu \mathrm{M}$ to $50 \mu \mathrm{M}$. This result of 218 inhibiting effect on degradation BPA because of increasingly BPA concentration mainly 219 explained by (i) The intermediate oxidation products of BPA in the UV/nitrate process 220 would be generated inevitably and increasingly, and they can efficiently scavenge 221 reactive radicals. The high reactivity of various unintended products (e.g., nitrophenol) 222 with RNS proposed by R.C. Scholes et al. (2019) also confirmed this view. (ii) 223 Excessive addition of BPA weakened the penetration ability of UV, and the subsequent 224 effect was to reduce the photon absorption efficiency of $\mathrm{NO}_{3}^{-}$. This phenomenon is 225 usually explained as the inner filter effect (Luo et al. 2020). To confirm this effect 226 resulted from BPA, the UV irradiation fraction absorbed by $\mathrm{NO}_{3}{ }^{-}$was determined and 227 the method is shown as Eq. (13).

$228 \mathrm{f}_{\mathrm{NO}_{3}^{-}}=\frac{\varepsilon_{\mathrm{NO}_{3}^{-}}\left[\mathrm{NO}_{3}^{-}\right]}{\varepsilon_{\mathrm{NO}_{3}^{-}}\left[\mathrm{NO}_{3}^{-}\right]+\varepsilon_{\mathrm{BPA}}[\mathrm{BPA}]}$

229 Where $\mathrm{f}_{\mathrm{NO}_{3}^{-}}$represent the UV irradiation fraction of $\mathrm{NO}_{3}{ }^{-}$absorption, $\varepsilon_{\mathrm{BPA}}$ and $\varepsilon_{\mathrm{NO}_{3}^{-}}$ 230 represent the molar extinction coefficients of $\mathrm{BPA}\left(\varepsilon_{\mathrm{BPA}}=750 \mathrm{M}^{-1} \cdot \mathrm{cm}^{-1}\right)$ and $\mathrm{NO}_{3}^{-}\left(\varepsilon_{\mathrm{NO}_{3}^{-}}=\right.$ $2313.51 \mathrm{M}^{-1} \cdot \mathrm{cm}^{-1}$ ) at $254 \mathrm{~nm}$, respectively (Duca et al. 2017; Goulart de Araujo et al. 2017). 232 The nitrate concentration and initial BPA concentration are expressed by $\left[\mathrm{NO}_{3}{ }^{-}\right]$and 233 [BPA], respectively. According to the results of calculations, we can find that $\mathrm{f}_{\mathrm{NO}_{3}^{-}}$ 
234 decreased sharply as the increase of [BPA], i.e., $96.6 \%$ at $5 \mu \mathrm{M}$ BPA $v s .73 .7 \%$ at 50

$235 \mu \mathrm{M}$ BPA. This data revealed that the inner filter effect of BPA $(5 \sim 50 \mu \mathrm{M})$ in this study

236 should be greatly appreciated.

$237 \quad 3.4$ Effect of $\mathrm{pH}$ value

238 Different $\mathrm{pH}$ values $(5,7,9,10$, and 11) were selected to assess the effect of varying 239 solution $\mathrm{pH}$ values on BPA degradation. The $\mathrm{pH}$ values were chosen according to the $240 \mathrm{pKa}$ of BPA $\left(\mathrm{pKa}_{1}=9.59, \mathrm{pKa}_{2}=10.2\right)$ for the reason that the $\mathrm{pH}$ value can change the 241 charge of the compound resulting in altering the molar extinction coefficient of the 242 compound and sometimes even alter the transformation pathway (Gao et al. 2010; Kang 243 et al. 2018; Kosky et al. 1991; Lu et al. 2013). As presented in Fig. 6, the $k_{\text {obs }}$ had a 244 slight increase (i.e., $8.687 \times 10^{-5}$ to $9.969 \times 10^{-5}$ ) with the $\mathrm{pH}$ value from 5 to 9 . 245 Nevertheless, early studies have shown that solution pH (ranging from 4 to 9) does not 246 affect the quantum yield of $\cdot \mathrm{OH}$ (Zellner et al. 1990). Therefore, characteristics and 247 existing forms of BPA at different $\mathrm{pH}$ values were given more attention in this study. 248 Actually, the absorption coefficient of BPA increased remarkably with $\mathrm{pH} 4$ to 11 at $249254 \mathrm{~nm}$ reported by Kang et al. (2018). Therefore, it is not difficult to explain that when 250 the photon absorption capacity of BPA increased, the UV direct degradation efficiency 251 naturally rose.

252 However, when solution $\mathrm{pH}$ higher than or equal to $10, k_{\text {obs }}$ rapidly grow, and the $k_{\text {obs }}$ 253 at $\mathrm{pH} 10$ was almost twice times as high as that at $\mathrm{pH}$ 9. It seems that only the change 254 of molar absorption coefficient can not perfectly illustrate this phenomenon. Through 
an enormous amount of previous studies, it was found that, as the solution $\mathrm{pH}$ exceeded the pKa of BPA, the deprotonation degree of BPA enhanced and the concentration of

257 ionic BPA rose as the $\mathrm{pH}$ value increasing (Lu et al. 2013; Wu et al. 2021). Furthermore,

258 the ionic form of BPA (i.e., bisphenolate anion) is more likely to be attacked by reactive

259 species, resulting in structural destruction (Ding et al. 2020; Kosky et al. 1991; Lee

260 \&von Gunten 2012; Wu et al. 2021). As further shown in Fig. 7, without $\mathrm{NO}_{3}^{-}$, the

261 removal ratio of BPA by UV photolysis at $\mathrm{pH} 11$ was so much more than that at $\mathrm{pH} 7$.

262 These results also indicate that the above elucidated about the reason of $\mathrm{pH}$ value

263 affecting the degradation of BPA is reasonable. Additionally, comparable results were

264 stated in previous studies in which alkaline conditions can facilitate BPA degradation

265 (Wu et al. 2016a).

$266 \quad 3.5$ Effect of $\mathrm{HCO}_{3}{ }^{-} / \mathrm{CO}_{3}{ }^{2-}$

267 The effect of $\mathrm{HCO}_{3}{ }^{-} / \mathrm{CO}_{3}{ }^{2-}(0 \sim 10 \mathrm{mM})$ on BPA degradation was then explored. As

268 shown in Fig. 8, the decomposition rate of BPA rose as $\mathrm{HCO}_{3}{ }^{-} / \mathrm{CO}_{3}{ }^{2-}$ concentration 269 increasing in the solution. The $k_{\mathrm{obs}}$ was $1.535 \times 10^{-4}$ at $10 \mathrm{mM} \mathrm{HCO}{ }^{-} / \mathrm{CO}_{3}{ }^{2-}$ that was $27055.92 \%$ higher than that of the control experiment. Traditionally, $\mathrm{HCO}_{3}{ }^{-}$and $\mathrm{CO}_{3}{ }^{2-}$ are 271 effectual scavengers of $\cdot \mathrm{OH}$, as demonstrated in Eqs. (14) (15) (Buxton et al. 1988).

$272 \quad \mathrm{HCO}_{3}^{-}+\cdot \mathrm{OH} \rightarrow \mathrm{CO}_{3}^{--}+\mathrm{H}_{2} \mathrm{O}, \quad k=8.5 \times 10^{6} \mathrm{M}^{-1} \mathrm{~s}^{-1}$

$273 \quad \mathrm{CO}_{3}^{2-}+\cdot \mathrm{OH} \rightarrow \mathrm{CO}_{3}^{--}+\mathrm{OH}^{-}, \quad k=3.9 \times 10^{8} \mathrm{M}^{-1} \mathrm{~s}^{-1}$

274 Previous studies reported that as an important one-electron oxidant, the $\mathrm{CO}_{3}{ }^{-}$has 275 relatively high reaction rates with electron-rich aromatic compounds (e.g., phenolic and 

hard to conclude that the equilibrium shifted to the right side due to $\cdot \mathrm{OH}$ scavenged by accumulative $\cdot \mathrm{NO}_{2}$.

\subsection{Effect of $\mathrm{Cl}^{-}$}

As a common anion in the environment, the effect of $\mathrm{Cl}^{-}$in $\mathrm{UV} /$ nitrate was also explored. Fig. 9 represented the result that $\mathrm{Cl}^{-}$had not outstanding inhibition or 284 acceleration BPA degradation (i.e., $k_{\mathrm{obs}}=9 \sim 10 \times 10^{-5} \mathrm{~s}^{-1}, \mathrm{Cl}^{-}$concentration varies from 0 285 to $10 \mathrm{mM}$ ). In general, some chlorine species, like $\mathrm{Cl} \cdot \mathrm{Cl}_{2}^{-}$, and $\mathrm{ClOH}^{-}$, may be 286 generated due to $\mathrm{Cl}^{-}$reacting with $\cdot \mathrm{OH}$ (Eq. (16) (18)) (Jayson et al. 1973; Yang et al. 287 2014).

$k_{+}=2.1 \times 10^{10} \mathrm{M}^{-1} \mathrm{~s}^{-1}, k_{-}=1.1 \pm 0.4 \times 10^{5} \mathrm{M}^{-1} \mathrm{~s}^{-1}$

294 Of note, these reactions are reversible and the reaction of forming $\mathrm{Cl} \cdot$ (Eq. (17)) 295 usually is significant at low $\mathrm{pH}$. While this experiment was conducted in neutral 296 conditions. Additionally, despite the above reaction occurred, those chlorine radicals do 
298 (Fang et al. 2014; Kong et al. 2016). Hence, the effect of $\mathrm{Cl}^{-}$on BPA degradation can 299 be neglected in this work.

\subsection{Effect of NOM}

301 As widespread substances in the environment, the effect of NOM on degradation 302 efficiency was also investigated (0 5mg-C/L). As depicted in Fig. 10, the $k_{\text {obs }}$ decreased 303 with the NOM concentration increasing. Furthermore, compared with the UV/nitrate 304 system without NOM, the $k_{\text {obs }}$ with NOM of $5 \mathrm{mg}-\mathrm{C} / \mathrm{L}$ was lower $62.0 \%$. This 305 phenomenon that NOM inhibited BPA degradation in UV/nitrate process can be 306 interpreted as follows:

307 On the one hand, $\mathrm{NOM}$ is an effective scavenger of $\cdot \mathrm{OH}\left(k_{\mathrm{NOM}} \cdot \mathrm{OH}=3.3 \times 10^{8} \mathrm{Mc}^{-1} \mathrm{~s}^{-}\right.$ $308{ }^{1}$ ) which lead to decrease $[\cdot \mathrm{OH}]_{\mathrm{ss}}$ and reduct reacting opportunities of $\cdot \mathrm{OH}$ with $\mathrm{BPA}$ or 309 intermediate products (Ahn et al. 2017). Although some organic radicals may produce 310 resulting from electron transfer reaction of $\cdot \mathrm{OH}$ with $\mathrm{NOM}$, the reactivities of those 311 radicals are lower than $\mathrm{OH}$ (Luo et al. 2019). On the other hand, NOM, whose molar 312 absorption coefficient is $\varepsilon=3.15 \mathrm{~L} \cdot \mathrm{mg}^{-1} \mathrm{~m}^{-1}$, served as an inner filter for UV (Fang et al. 313 2014). Therefore, the ability of nitrate to absorb photons was reduced extremely, which 314 led to the decrease of the reaction efficiency of producing $\cdot \mathrm{OH}$.

\subsection{Intermediate products and proposed transformation pathways}

316 The changes of TOC of BPA before and after reaction in the UV/nitrate process are 317 depicted in Fig. S3, indicating that mineralization was little in this study. BPA 
318 predominantly transformed small organic compounds. Based on the results of

$319 \mathrm{LC} / \mathrm{MS} / \mathrm{MS}$, the possible transformation pathways of BPA in the UV/nitrate process are

320 elucidated in Fig. 11. Intermediate products and detailed information are supplied in

321 Table. S4 and Fig. S4. According to Gao et al's (2020a) reaction mechanism study on

322 BPA degradation in UV/SPC, the BPA transformation pathways can be divided into four

323 aspects in this study (i.e., (1) isopropylidene bridge cleavage, (2) isopropylidene

324 modification, (3) ring modification, and (4) ring cleavage.). First, $\cdot \mathrm{OH}$ could attack the

325 electron-rich isopropyl $\mathrm{C}$ atom of BPA, resulting in the formation of 4-isopropyl phenol

$326\left(\mathrm{~B}_{135}, \mathrm{~m} / \mathrm{z}=135.19\right)$ and phenol $\left(\mathrm{B}_{93}, \mathrm{~m} / \mathrm{z}=93.1\right)$. Therefore, $\mathrm{B}_{199}(\mathrm{~m} / \mathrm{z}=199.11)$, a

327 nitrobenzene derivative, could be produced because of the rapid reaction of $\cdot \mathrm{OH}$

328 and $\cdot \mathrm{NO}_{2}$ with phenol. Based on the consideration of the reaction activation energy and

329 Gibbs free energy, the ortho position of BPA is more likely to be hydroxylated than the

330 meta and para positions (Dai et al. 2016). Hence, $B_{151}(\mathrm{~m} / \mathrm{z}=151.19)$ generated by

331 hydroxylation. And through further oxidation and possible degradation of BPA, $\mathrm{B}_{131}$

$332(\mathrm{~m} / \mathrm{z}=131.16)$ and $\mathrm{B}_{136}(\mathrm{~m} / \mathrm{z}=136.14)$ were generated. Besides, with the aromatic ring

333 of $\mathrm{B}_{151} \mathrm{H}$-abstraction and further oxidation, a benzoquinone derivative (i.e., $\mathrm{B}_{181 \text {, }}$

$334 \mathrm{~m} / \mathrm{z}=181.17)$ formed. All the above products were further oxidated and occurred ring

335 cleavage, some small-molecule organic compounds (e.g., $\mathrm{B}_{97}$ (m/z=97.14), $\mathrm{B}_{79}$

$336(\mathrm{~m} / \mathrm{z}=79.13)$, and $\left.\mathrm{B}_{92}(\mathrm{~m} / \mathrm{z}=92.09)\right)$ formed. Besides, the mineralization of partial

337 organic compounds could produce inorganic compounds such as $\mathrm{CO}_{2}, \mathrm{H}_{2} \mathrm{O}$, and $\mathrm{NO}_{3}$ -

3383.9 Acute toxicity and effect of actual waters components 
339 The change regularity in acute toxicity of BPA in the UV/nitrate process is 340 demonstrated in Fig. 12. The acute toxicity is represented using the ratio of 341 bioluminescence of the solution before and after treatment (i.e., $\mathrm{L} / \mathrm{L}_{0}$ ). When Vibrio 342 fischeri contacted with BPA solution for $900 \mathrm{~s}$ and $1800 \mathrm{~s}$, the inhibition percentages 343 were about $10.2 \%$ and $12.1 \%$, respectively. These data show nonnegligible acute 344 toxicity of BPA to $V$. fischeri. As expected, the toxicity increased obviously in the initial 345 reaction time. In detail, the $\mathrm{L} / \mathrm{L}_{0}$ decreased from 0.88 to 0.74 when reaction time 346 increased from 0 to $1200 \mathrm{~s}$. The formation of more toxic transformation products, 347 including those containing aromatic ring compounds (e.g., phenol), benzoquinone 348 derivatives, and nitrobenzene derivatives was to blame for this reasult (de Freitas et al. 349 2017; Han et al. 2015). Subsequently, the acute toxicity gradually decayed as the 350 experiment time was longer than $1200 \mathrm{~s}$. This phenomenon indicated that lower toxic 351 products were formed with the further reaction.

352 To investigate the application of the UV/nitrate system in the real environment, BPA 353 degradation experiments were also conducted in several actual waters. As is 354 demonstrated in Fig. 13, compared with de-ionized water, BPA degradation in surface 355 water was inhibited. From Table. S3, the possible reason for this phenomenon is the 356 relatively high concentration of $\mathrm{NOM}(\mathrm{TOC}=4.115 \mathrm{mg}-\mathrm{C} / \mathrm{L})$. Although the total 357 alkalinity was as high as $230.63 \mathrm{mg} \mathrm{CaCO} / \mathrm{L}$ (i.e., $2.3 \mathrm{mM} \mathrm{CO}_{3}{ }^{2-}$ ) and the $\mathrm{NO}_{3}{ }^{-}$ 358 concentration was $10.418 \mathrm{mg}-\mathrm{N} / \mathrm{L}$ (i.e., $0.744 \mathrm{mM}$ ), the inhibition effect can not be offset. 359 In contrast, BPA decomposition rates in groundwater and drinking water were 
accelerated. The results can be ascribed to their high total alkalinity and low TOC (Table.

361 S3). Consequently, the decomposition of BPA and other EDCs in the UV/nitrate process

362 could become a reality theoretically. But the strict condition (e.g., needing a relatively

363 high concentration of $\mathrm{NO}_{3}^{-}$) limits the scope of its application. Numerous studies have

364 shown that high concentration $\mathrm{NO}_{3}{ }^{-}$and generated $\mathrm{NO}_{2}{ }^{-}$can harm human health (e.g.,

365 causing blue baby syndrome in infants) and animals as well as eutrophication of real

366 water bodies (Archna et al. 2012; Mohajeri et al. 2021). Besides, the generation of

367 harmful intermediate products (e.g., benzoquinone and nitrobenzene derivatives) and

368 possible enhanced acute toxicity results should be taken into consideration. As a result,

369 the UV/nitrate process is not a suitable technology to apply in drinking water treatment

370 plants, and its applications in the treatment of wastewater rich in nitrate also need

371 further studies.

\section{Conclusions}

373 In this work, the degradation of BPA in different effect factors was investigated, and

374 intermediate products and possible transformation pathways were proposed. The 375 conclusions are as follows:

376 (i) $[\cdot \mathrm{OH}]_{\mathrm{ss}}$ was $5.26 \times 10^{-15} \mathrm{M}$ at control conditions in $\mathrm{UV} /$ nitrate process. When BPA 377 was degraded in the UV/nitrate process for $3600 \mathrm{~s}$, the contributions of $\mathrm{UV}, \cdot \mathrm{OH}$, and 378 RNS accounted for $4.1 \%, 52.7 \%$, and $43.2 \%$, respectively.

379 (ii) BPA could be effectively degraded in UV/nitrate process, $k_{\text {obs }}$ increased with 380 increasing addition of $\mathrm{NO}_{3}^{-}(0 \sim 50 \mathrm{mM})$ while decreased with increasing of BPA 
concentration $(5 \sim 50 \mu \mathrm{M})$.

382 (iii) The degradation efficiency of BPA promoted with $\mathrm{pH}$ value rise in the range of 3835 to 11.

384 (iv) Increasing the concentration of $\mathrm{HCO}_{3}{ }^{-} / \mathrm{CO}_{3}{ }^{2-}(0 \sim 10 \mathrm{mM})$ can accelerate the BPA 385 degradation, while the effect of $\mathrm{Cl}^{-}(0 \sim 20 \mathrm{mM})$ could be ignored when the $\mathrm{Cl}^{-}$dosage 386 less than $20 \mathrm{mM}$, and adding NOM (0 5mg-C/L) acutely reduced the BPA degradation 387 due to the dual role of $\cdot \mathrm{OH}$ scavenged and serving as an inner filter.

388 (v) BPA decomposition was mainly divided into four aspects, and many intermediate 389 products including benzoquinone and nitrobenzene derivatives could form in the $390 \mathrm{UV} /$ nitrate process.

391 (vi) The acute toxicity of BPA in the UV/nitrate process increased slightly in the 392 initial $1200 \mathrm{~s}$ because of more toxic intermediate products produced and then gradually 393 declined due to the further decomposition of intermediates. UV/nitrate process is not 394 very suitable to apply in drinking water treatment plants and its application with other 395 technology needs to be studied further.

396 Author contributions All authors contributed to the study conception and design.

397 Material preparation, data collection, and analysis were performed by Zhiquan Li, 398 Shishun Wang, Fumiao Zhang, and Mingli Li. The first draft of the manuscript was 399 written by Zhiquan $\mathrm{Li}$, and all authors commented on previous versions of the 400 manuscript. All authors read and approved the final manuscript.

401 Congwei Luo has made significant contributions to the experimental research ideas, 
402 finalized the version to be published, and provided project funding support for this 403 paper. Xiaoxiang Cheng and Qiao Ma have made in-depth revisions to the manuscript 404 on important technical content and finalized the version to be published. Fengxun Tan 405 and Daoji Wu supervised the implementation of research activities and finalized the 406 version to be published.

407 Funding This study was supported by the Central Government Guides the Local 408 Science and Technology Development Special Project (Grant Nos. 2020ZY0068), 409 China Postdoctoral Science Foundation (Grant Nos. 2020M672085), National Natural 410 Science Foundation of China (Grant Nos. 51908335), the post-doctoral innovation 411 project of Shandong Province (Grant Nos. 317202002023).

412 Availability of data and materials The datasets used and analyzed during the current 413 study are available from the corresponding author on reasonable request.

\section{Declarations}

415 Ethical approval Not applicable.

416 Consent to participate Not applicable.

417 Consent to publish Not applicable.

418 Competing interests The authors declare no competing interests.

419 References

420 Ahn Y, Lee D, Kwon M, Choi I-h, Nam S-N, Kang J-W (2017): Characteristics and fate 421 of natural organic matter during UV oxidation processes. Chemosphere 184, 960-968 
Archna, Sharma SK, Sobti RC (2012): Nitrate Removal from Ground Water: A Review. E-Journal of Chemistry 9, 154616

Bergman Å, Heindel JJ, Jobling S, Kidd K, Zoeller TR, Organization WH (2013): State of the science of endocrine disrupting chemicals 2012. World Health Organization

Bu L, Zhu N, Li C, Huang Y, Kong M, Duan X, Dionysiou DD (2020): Susceptibility of atrazine photo-degradation in the presence of nitrate: Impact of wavelengths and significant role of reactive nitrogen species. Journal of Hazardous Materials 388,121760

Burman A, Garcia-Milian R, Whirledge S (2020): Gene X environment: the cellular environment governs the transcriptional response to environmental chemicals. Hum Genomics 14, 19-19

Buxton GV, Greenstock CL, Helman WP, Ross AB (1988): Critical Review of rate constants for reactions of hydrated electrons, hydrogen atoms and hydroxyl radicals $\left(\cdot \mathrm{OH} / \cdot \mathrm{O}^{-}\right.$in Aqueous Solution. Journal of Physical and Chemical Reference Data 17, 513-886

Chaves FP, Gomes G, Della-Flora A, Dallegrave A, Sirtori C, Saggioro EM, Bila DM (2020): Comparative endocrine disrupting compound removal from real wastewater by $\mathrm{UV} / \mathrm{Cl}$ and $\mathrm{UV} / \mathrm{H} 2 \mathrm{O} 2$ : Effect of $\mathrm{pH}$, estrogenic activity, transformation products and toxicity. Science of The Total Environment 746, 141041 
Dai F, Fan X, Stratton GR, Bellona CL, Holsen TM, Crimmins BS, Xia X, Mededovic Thagard S (2016): Experimental and density functional theoretical study of the effects of Fenton's reaction on the degradation of Bisphenol A in a high voltage plasma reactor. Journal of Hazardous Materials 308, 419-429

de Freitas EN, Bubna GA, Brugnari T, Kato CG, Nolli M, Rauen TG, Peralta Muniz Moreira RdF, Peralta RA, Bracht A, de Souza CGM, Peralta RM (2017): Removal of bisphenol A by laccases from Pleurotus ostreatus and Pleurotus pulmonarius and evaluation of ecotoxicity of degradation products. Chemical Engineering Journal 330, 1361-1369

Diamanti-Kandarakis E, Bourguignon J-P, Giudice LC, Hauser R, Prins GS, Soto AM, Zoeller RT, Gore AC (2009): Endocrine-Disrupting Chemicals: An Endocrine Society Scientific Statement. Endocrine Reviews 30, 293-342

Ding Y, Hu Y, Peng X, Xiao Y, Huang J (2020): Micro-nano structured CoS: An efficient catalyst for peroxymonosulfate activation for removal of bisphenol A. Separation and Purification Technology 233, 116022

Duca C, Imoberdorf G, Mohseni M (2017): Effects of inorganics on the degradation of micropollutants with vacuum UV (VUV) advanced oxidation. Journal of Environmental Science and Health, Part A 52, 524-532

Fang J, Fu Y, Shang C (2014): The Roles of Reactive Species in Micropollutant Degradation in the UV/Free Chlorine System. Environmental Science \& Technology 48, 1859-1868 
Gao B, Lim TM, Subagio DP, Lim T-T (2010): Zr-doped TiO2 for enhanced photocatalytic degradation of bisphenol A. Applied Catalysis A: General 375, 107-115

Gao J, Duan X, O’Shea K, Dionysiou DD (2020a): Degradation and transformation of bisphenol A in UV/Sodium percarbonate: Dual role of carbonate radical anion. Water Research 171, 115394

Gao J, Luo C, Gan L, Wu D, Tan F, Cheng X, Zhou W, Wang S, Zhang F, Ma J (2020b): A comparative study of UV/H2O2 and UV/PDS for the degradation of micropollutants: kinetics and effect of water matrix. Environmental Science and Pollution Research 27, 24531-24541

Gewurtz SB, Tardif G, Power M, Backus SM, Dove A, Dubé-Roberge K, Garron C, King M, Lalonde B, Letcher RJ, Martin PA, McDaniel TV, McGoldrick DJ, Pelletier M, Small J, Smyth SA, Teslic S, Tessier J (2021): Bisphenol A in the Canadian environment: A multimedia analysis. Science of The Total Environment 755, 142472

Gmurek M, Olak-Kucharczyk M, Ledakowicz S (2017): Photochemical decomposition of endocrine disrupting compounds - A review. Chemical Engineering Journal $310,437-456$

Goldstein S, Rabani J (2007): Mechanism of Nitrite Formation by Nitrate Photolysis in Aqueous Solutions: The Role of Peroxynitrite, Nitrogen Dioxide, and Hydroxyl Radical. Journal of the American Chemical Society 129, 10597-10601 
Gonzalez MC, Braun AM (1995): VUV photolysis of aqueous solutions of nitrate and nitrite. Research on Chemical Intermediates 21, 837-859

Gore AC, Krishnan K, Reilly MP (2019): Endocrine-disrupting chemicals: Effects on neuroendocrine systems and the neurobiology of social behavior. Hormones and Behavior 111, 7-22

Goulart de Araujo L, Santos FdS, Teixeira ACSC (2017): Degradation of bisphenol A by the $\mathrm{UV}$ and $\mathrm{UV} / \mathrm{H} 2 \mathrm{O} 2$ processes: Evaluation of process variables through experimental design. The Canadian Journal of Chemical Engineering 95, 22782285

Han Q, Wang H, Dong W, Liu T, Yin Y, Fan H (2015): Degradation of bisphenol A by ferrate(VI) oxidation: Kinetics, products and toxicity assessment. Chemical Engineering Journal 262, 34-40

Hu Y, Yan X, Shen Y, Di M, Wang J (2019): Occurrence, behavior and risk assessment of estrogens in surface water and sediments from Hanjiang River, Central China. Ecotoxicology 28, 143-153

Huang Y, Kong M, Westerman D, Xu EG, Coffin S, Cochran KH, Liu Y, Richardson SD, Schlenk D, Dionysiou DD (2018): Effects of HCO3- on Degradation of Toxic Contaminants of Emerging Concern by UV/NO3-. Environmental Science \& Technology 52, 12697-12707

Jayson GG, Parsons BJ, Swallow AJ (1973): Some simple, highly reactive, inorganic chlorine derivatives in aqueous solution. Their formation using pulses of 
radiation and their role in the mechanism of the Fricke dosimeter. Journal of the Chemical Society, Faraday Transactions 1: Physical Chemistry in Condensed Phases 69, 1597

Jeong S, Jeon K-J, Park Y-K, Kim B-J, Chung K-H, Jung S-C (2020): Catalytic Properties of Microporous Zeolite Catalysts in Synthesis of Isosorbide from Sorbitol by Dehydration. Catalysts 10

Kahn LG, Philippat C, Nakayama SF, Slama R, Trasande L (2020): Endocrinedisrupting chemicals: implications for human health. The Lancet Diabetes \& Endocrinology 8, 703-718

Kang Y-M, Kim M-K, Zoh K-D (2018): Effect of nitrate, carbonate/bicarbonate, humic the transformation of organic micropollutants during oxidative water treatment. 
Lu N, Lu Y, Liu F, Zhao K, Yuan X, Zhao Y, Li Y, Qin H, Zhu J (2013): H3PW12O40/TiO2 catalyst-induced photodegradation of bisphenol A (BPA): Kinetics, toxicity and degradation pathways. Chemosphere 91, 1266-1272 comparative study on the oxidation kinetics of atrazine by $\mathrm{UV} / \mathrm{H} 2 \mathrm{O} 2$, UV/HSO5- and UV/S2O82-. Water Research 80, 99-108

Luo C, Gao J, Wu D, Jiang J, Liu Y, Zhou W, Ma J (2019): Oxidation of 2,4bromophenol by UV/PDS and formation of bromate and brominated products: A comparison to UV/H2O2. Chemical Engineering Journal 358, 1342-1350

Luo C, Gao J, Ma Q, Wu D, Cheng X, Jiang J, Zhou W, Yang Z, Ma J (2020): The bromate formation accompanied by the degradation of 2,4-bromophenol in

Mack J, Bolton JR (1999): Photochemistry of nitrite and nitrate in aqueous solution: a

Luo Y, Guo W, Ngo HH, Nghiem LD, Hai FI, Zhang J, Liang S, Wang XC (2014): A UV/peroxymonosulfate. Separation and Purification Technology 233, 116028 review. Journal of Photochemistry and Photobiology A: Chemistry 128, 1-13 review on the occurrence of micropollutants in the aquatic environment and their fate and removal during wastewater treatment. Science of The Total Environment 473-474, 619-641

Mohajeri P, Smith CMS, Chau HW, Lehto N (2021): ALLODUST augmented activated sludge single batch anaerobic reactor (AS-SBAnR) for high concentration 
551 Newbold RR, Padilla-Banks E, Snyder RJ, Phillips TM, Jefferson WN (2007): Developmental exposure to endocrine disruptors and the obesity epidemic. Reproductive Toxicology 23, 290-296

Rodríguez-Chueca J, Garcia-Cañibano C, Sarro M, Encinas Á, Medana C, Fabbri D, Calza P, Marugán J (2019): Evaluation of transformation products from chemical oxidation of micropollutants in wastewater by photoassisted generation of sulfate radicals. Chemosphere 226, 509-519

Rosenfeldt EJ, Linden KG (2004): Degradation of Endocrine Disrupting Chemicals Bisphenol A, Ethinyl Estradiol, and Estradiol during UV Photolysis and Advanced Oxidation Processes. Environmental Science \& Technology 38, $5476-5483$

Sato Y, Ishihara M, Fukuda K, Nakamura S, Murakami K, Fujita M, Yokoe H (2018): Behavior of Nitrate-Nitrogen and Nitrite-Nitrogen in Drinking Water. Biocontrol Science 23, 139-143

Scholes RC, Prasse C, Sedlak DL (2019): The Role of Reactive Nitrogen Species in Sensitized Photolysis of Wastewater-Derived Trace Organic Contaminants. A (BPA) in aqueous solution using advanced oxidation processes: UV/H2O2 
and UV/S2O82- oxidation systems. Journal of Environmental Management $156,266-275$

Sharma J, Mishra IM, Kumar V (2016): Mechanistic study of photo-oxidation of Bisphenol-A (BPA) with hydrogen peroxide (H2O2) and sodium persulfate (SPS). Journal of Environmental Management 166, 12-22

Vilarinho F, Sendón R, van der Kellen A, Vaz MF, Silva AS (2019): Bisphenol A in food as a result of its migration from food packaging. Trends in Food Science \& Technology 91, 33-65

Vione D, Maurino V, Pelizzetti E, Minero C (2004): Phenol Photonitration and Photonitrosation upon Nitrite Photolysis in basic solution. International Journal

Welshons WV, Nagel SC, vom Saal FS (2006): Large Effects from Small Exposures. of Environmental Analytical Chemistry 84, 493-504 Human Exposure. Endocrinology 147, s56-s69

Wu L, Jin X, Zhao T, Wang H, Dai Z (2021): Impact factors of the degradation of bisphenol A by nitrocellulose membrane under illumination. Journal of Environmental Sciences 100, 193-202

Wu W, Shan G, Wang S, Zhu L, Yue L, Xiang Q, Zhang Y, Li Z (2016a): Environmentally relevant impacts of nano-TiO2 on abiotic degradation of bisphenol A under sunlight irradiation. Environmental Pollution 216, 166-172

590 Wu Z, Fang J, Xiang Y, Shang C, Li X, Meng F, Yang X (2016b): Roles of reactive 
chlorine species in trimethoprim degradation in the UV/chlorine process: Kinetics and transformation pathways. Water Research 104, 272-282

593 Yang Y, Pignatello JJ, Ma J, Mitch WA (2014): Comparison of Halide Impacts on the Efficiency of Contaminant Degradation by Sulfate and Hydroxyl Radical-Based Advanced Oxidation Processes (AOPs). Environmental Science \& Technology 48, 2344-2351

Zellner R, Exner M, Herrmann H (1990): Absolute OH quantum yields in the laser photolysis of nitrate, nitrite and dissolved $\mathrm{H} 2 \mathrm{O} 2$ at 308 and $351 \mathrm{~nm}$ in the temperature range 278-353 K. Journal of Atmospheric Chemistry 10, 411-425 elimination of contaminants of emerging concern in the presence of residual nitrite: Roles of reactive nitrogen species. Water Research 178, 115829 
Figures
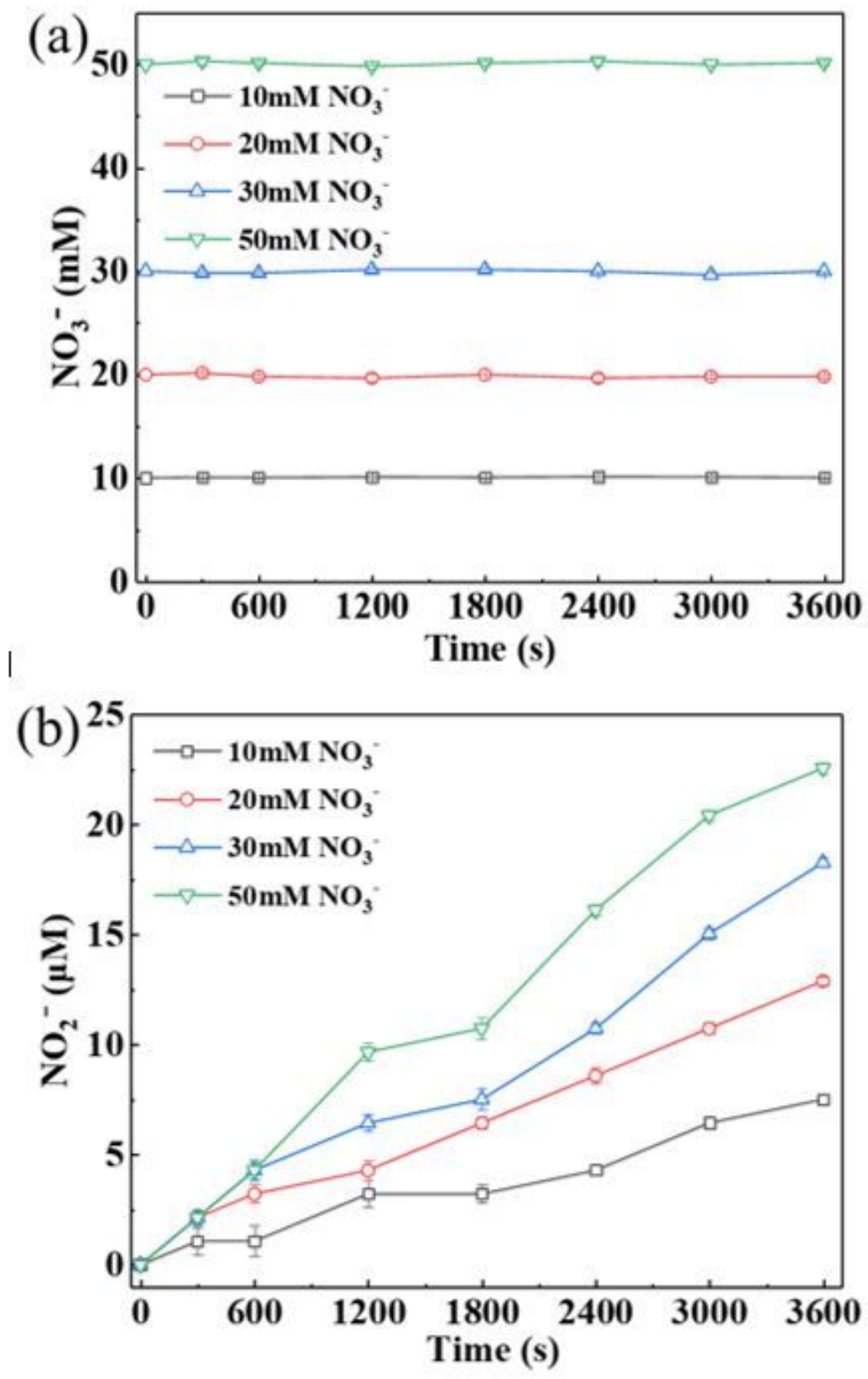

Figure 1

(a) Changes of NO3- concentration in the UV/nitrate process. (b) Changes of NO2- concentration in UV/nitrate process. Experimental conditions: [BPA] $=30 \mu \mathrm{M},[\mathrm{NO3}-]=10 \sim 50 \mathrm{mM}, \mathrm{pH}=7$, [phosphate] $=5$ $\mathrm{mM}$, time $=3600 \mathrm{~s}, \mathrm{I}=0.172 \mathrm{~mW} \mathrm{~cm}-2$. 


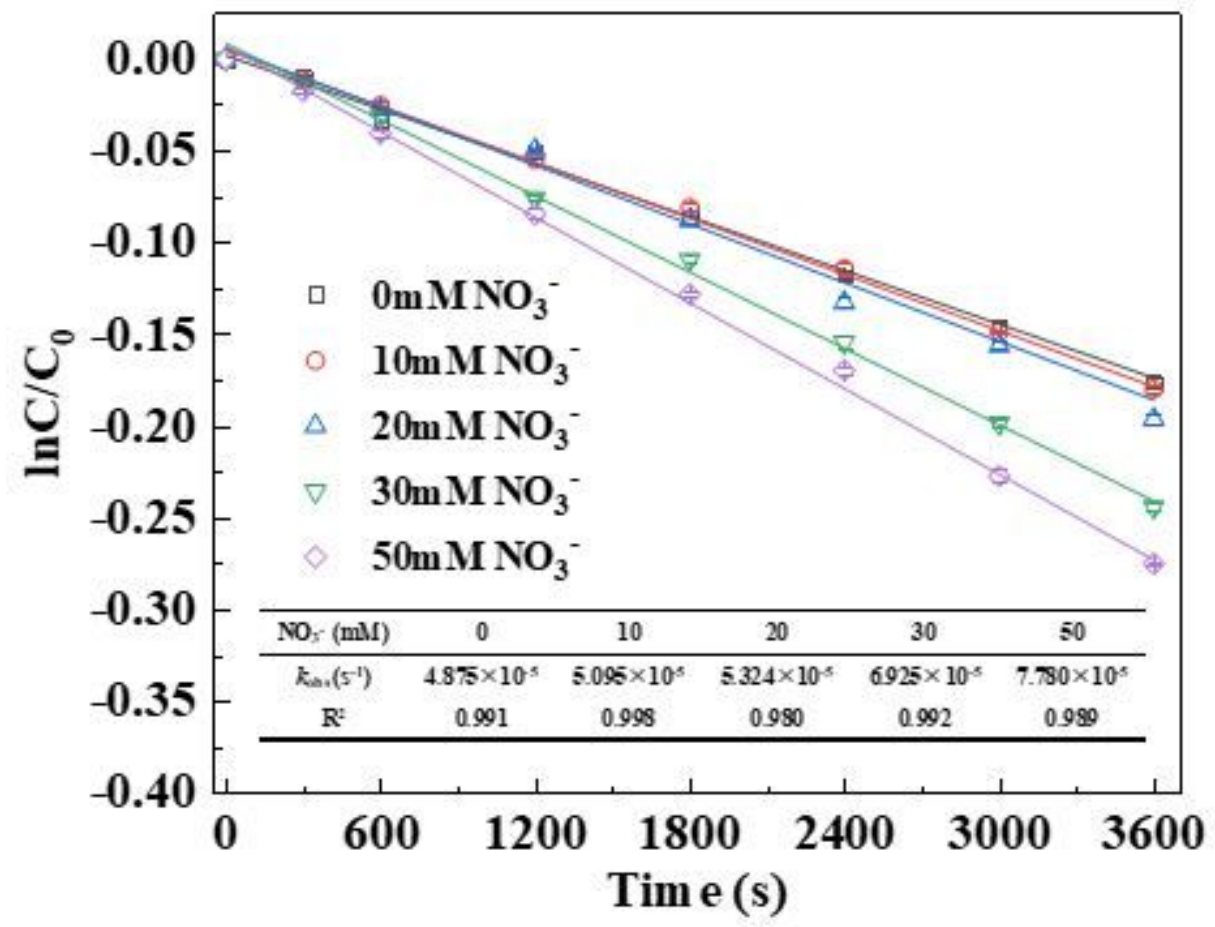

Figure 2

Degradation of NB in different concentrations of NO3-. Experimental conditions:[NB] $=50 \mu \mathrm{M},[\mathrm{BPA}]=30$ $\mu \mathrm{M},[\mathrm{NO3}]=0 \sim 50 \mathrm{mM}, \mathrm{pH}=7$, [phosphate] $=5 \mathrm{mM}$, time $=3600 \mathrm{~s}, \mathrm{I}=0.172 \mathrm{~mW} \cdot \mathrm{cm}-2$.

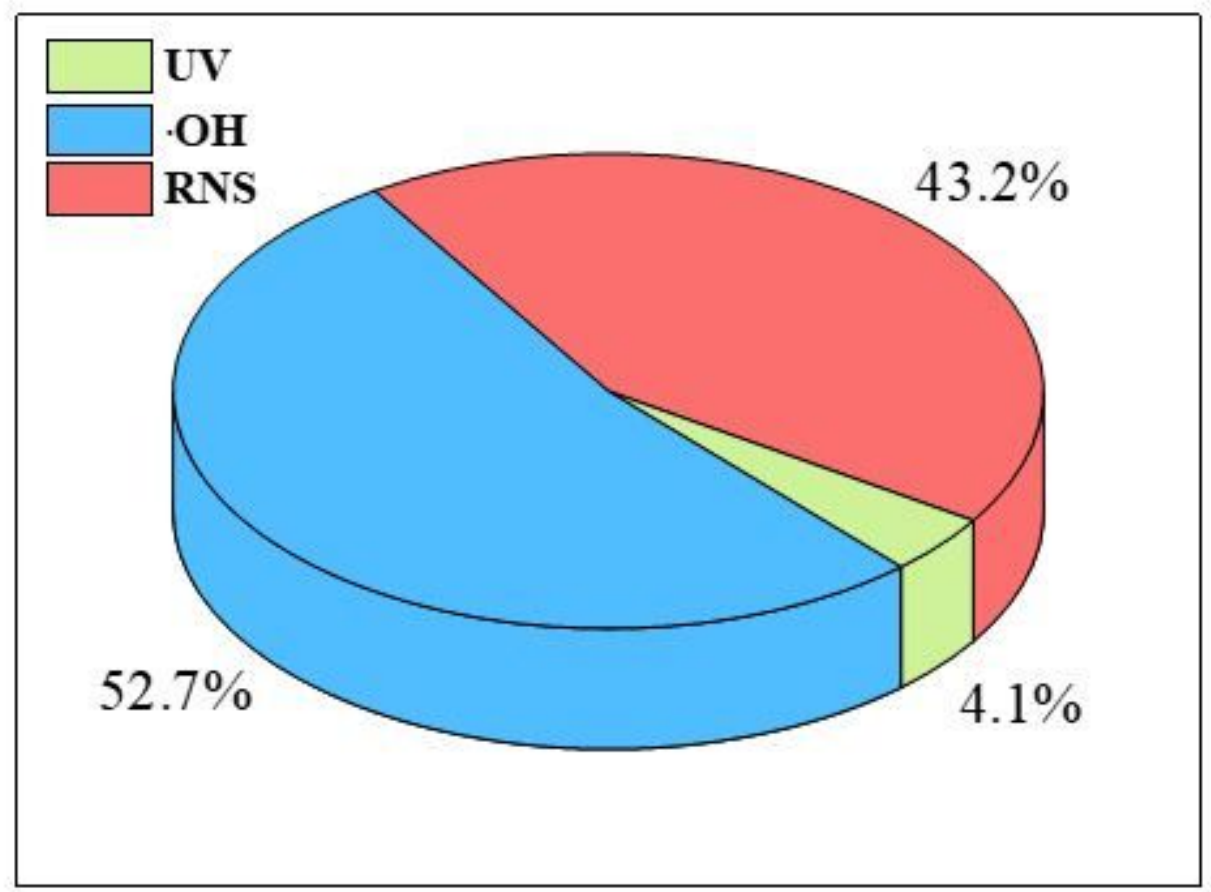

Figure 3 
Proportions of $\mathrm{UV}, \cdot \mathrm{OH}$, and RNS in the total removal ratio. Experimental conditions:[BPA] $=30 \mu \mathrm{M},[\mathrm{NO}-]$ $=30 \mathrm{mM}, \mathrm{pH}=7$, [phosphate] $=5 \mathrm{mM}$, time $=3600 \mathrm{~s}, \mathrm{I}=0.172 \mathrm{~mW} \mathrm{~cm}-2$.

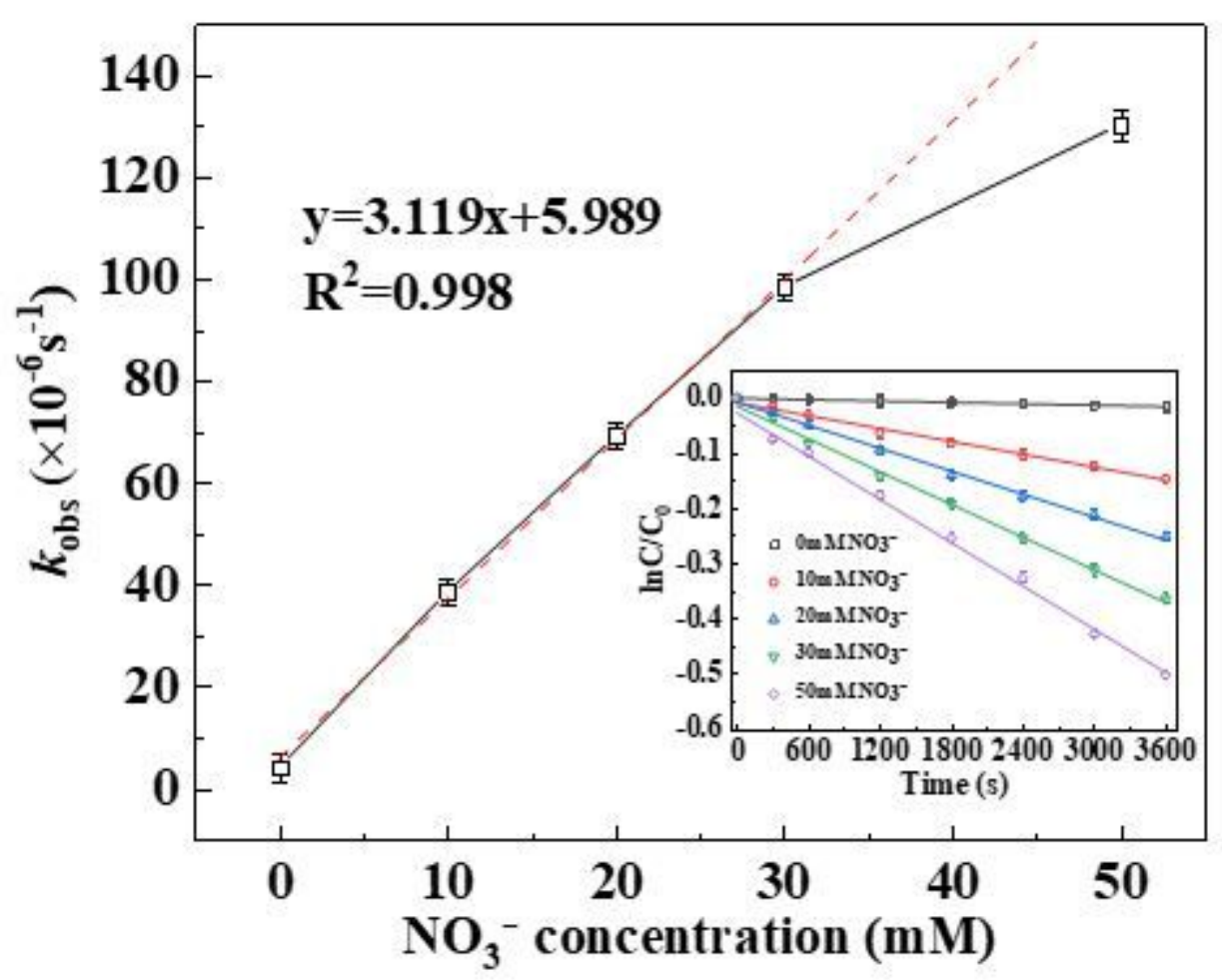

Figure 4

The changes of kobs with NO3- concentration in UV/nitrate process. Experimental conditions: $[\mathrm{BPA}]=30$ $\mu \mathrm{M},[\mathrm{NO3}]=0 \sim 50 \mathrm{mM}, \mathrm{pH}=7$, [phosphate] $=5 \mathrm{mM}$, time $=3600 \mathrm{~s}, \mathrm{I}=0.172 \mathrm{~mW} \cdot \mathrm{cm}-2$. 


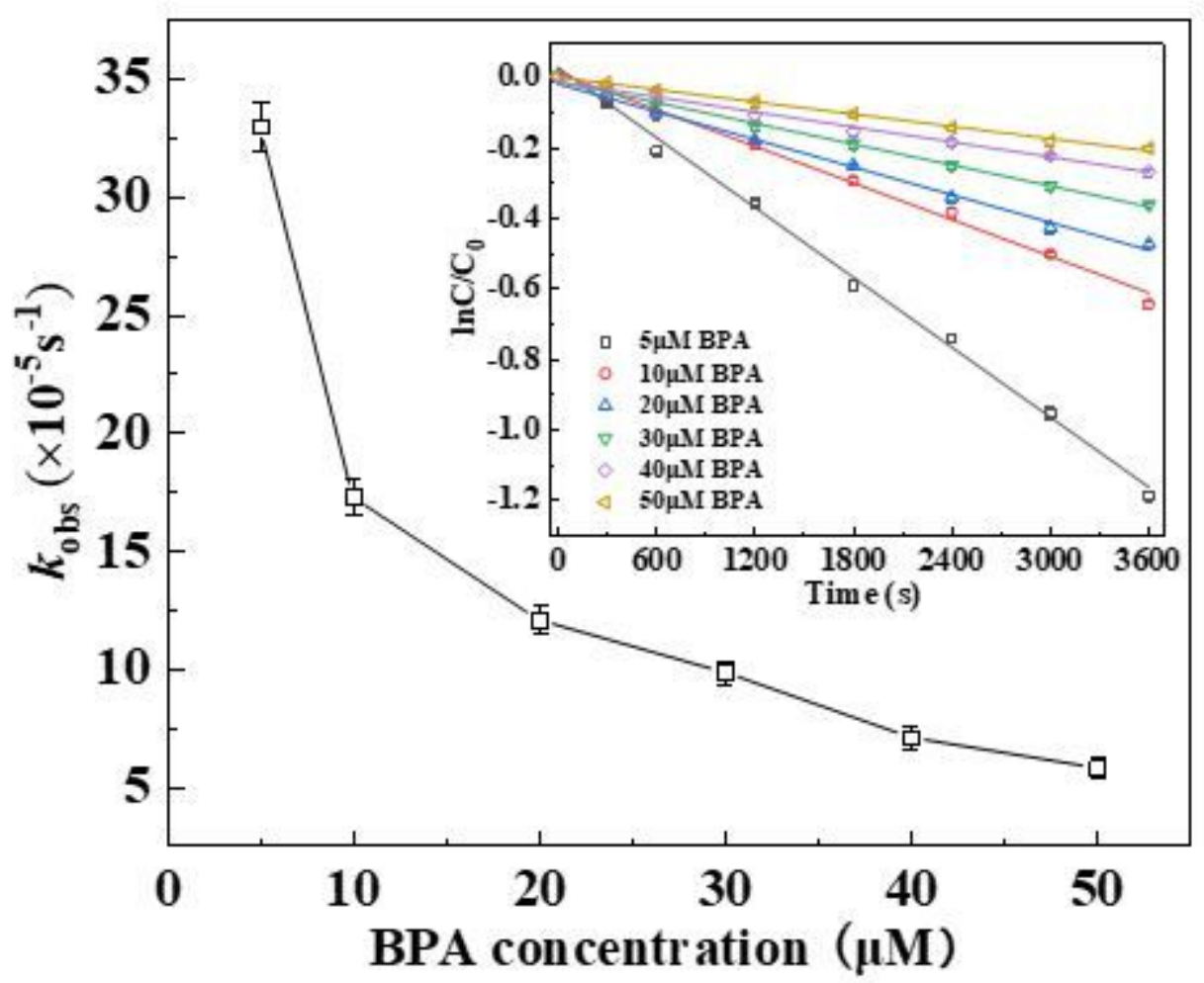

Figure 5

The changes of kobs with BPA concentration in UV/nitrate process. Experimental conditions:[BPA] = 5 50 $\mu \mathrm{M},[\mathrm{NO3}]=30 \mathrm{mM}, \mathrm{pH}=7$, [phosphate] $=5 \mathrm{mM}$, time $=3600 \mathrm{~s}, \mathrm{I}=0.172 \mathrm{~mW} \cdot \mathrm{cm}-2$.

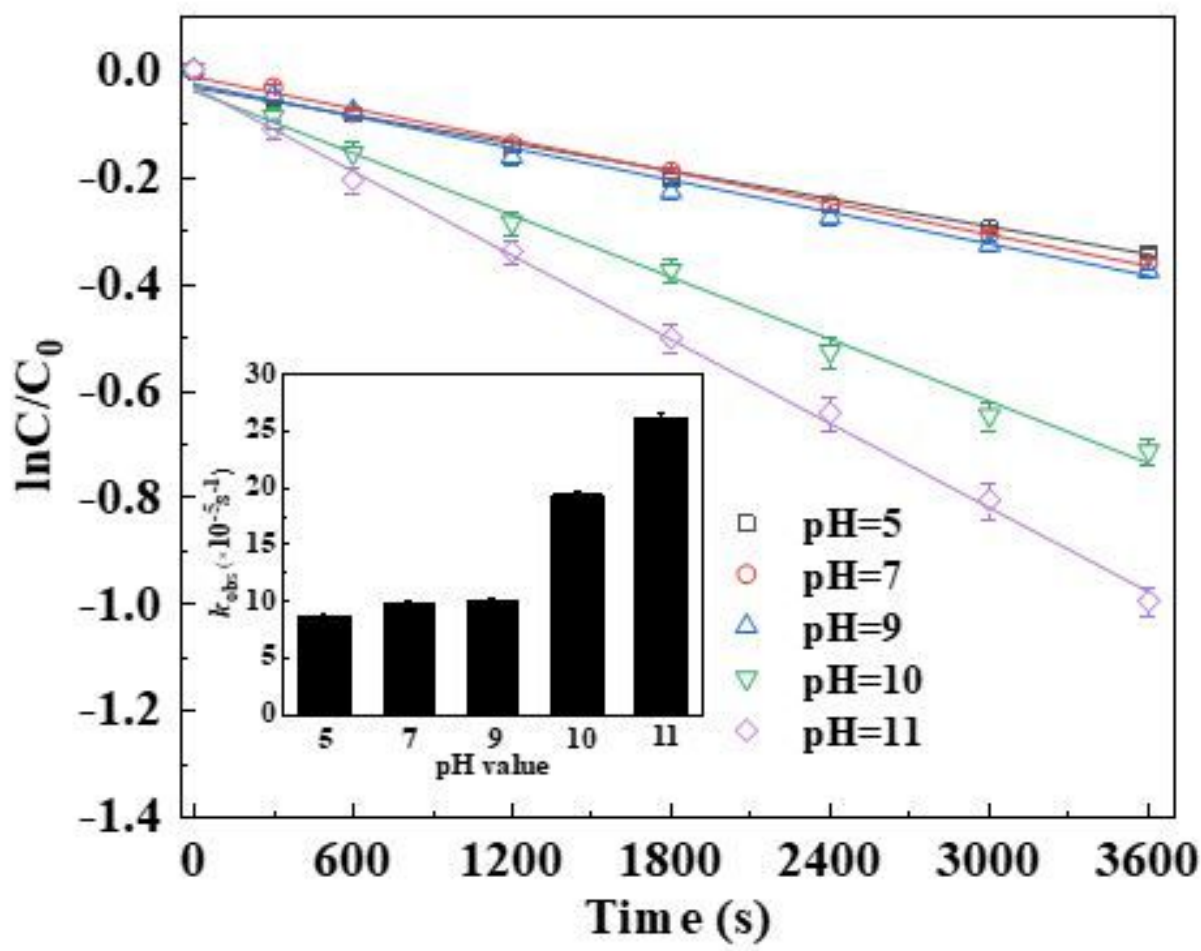

Figure 6 
Effect of $\mathrm{pH}$ on BPA degradation in UV/nitrate process. Experimental conditions:[BPA] $=30 \mu \mathrm{M}$, [NO3-] = $30 \mathrm{mM}, \mathrm{pH}=5,7,9,10$, and 11, [phosphate] $=5 \mathrm{mM}$, time $=3600 \mathrm{~s}, \mathrm{I}=0.172 \mathrm{~mW} \cdot \mathrm{cm}-2$.

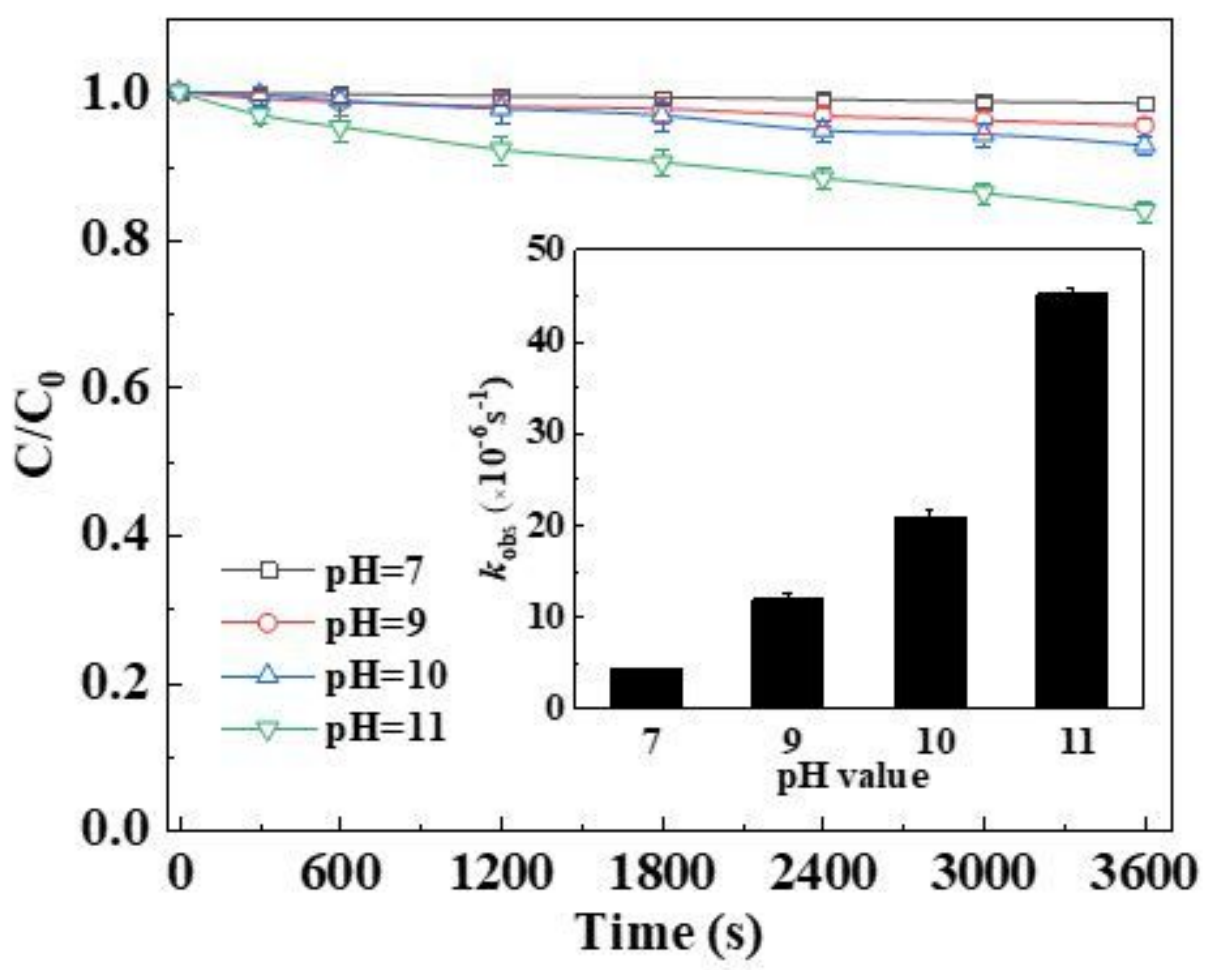

Figure 7

Effect of $\mathrm{pH}$ on BPA degradation in direct UV process. Experimental conditions:[BPA] $=30 \mu \mathrm{M},[\mathrm{NO}-]=30$ $\mathrm{mM}, \mathrm{pH}=7,9,10$, and 11, [phosphate] $=5 \mathrm{mM}$, time $=3600 \mathrm{~s}, \mathrm{I}=0.172 \mathrm{~mW} \cdot \mathrm{cm}-2$.

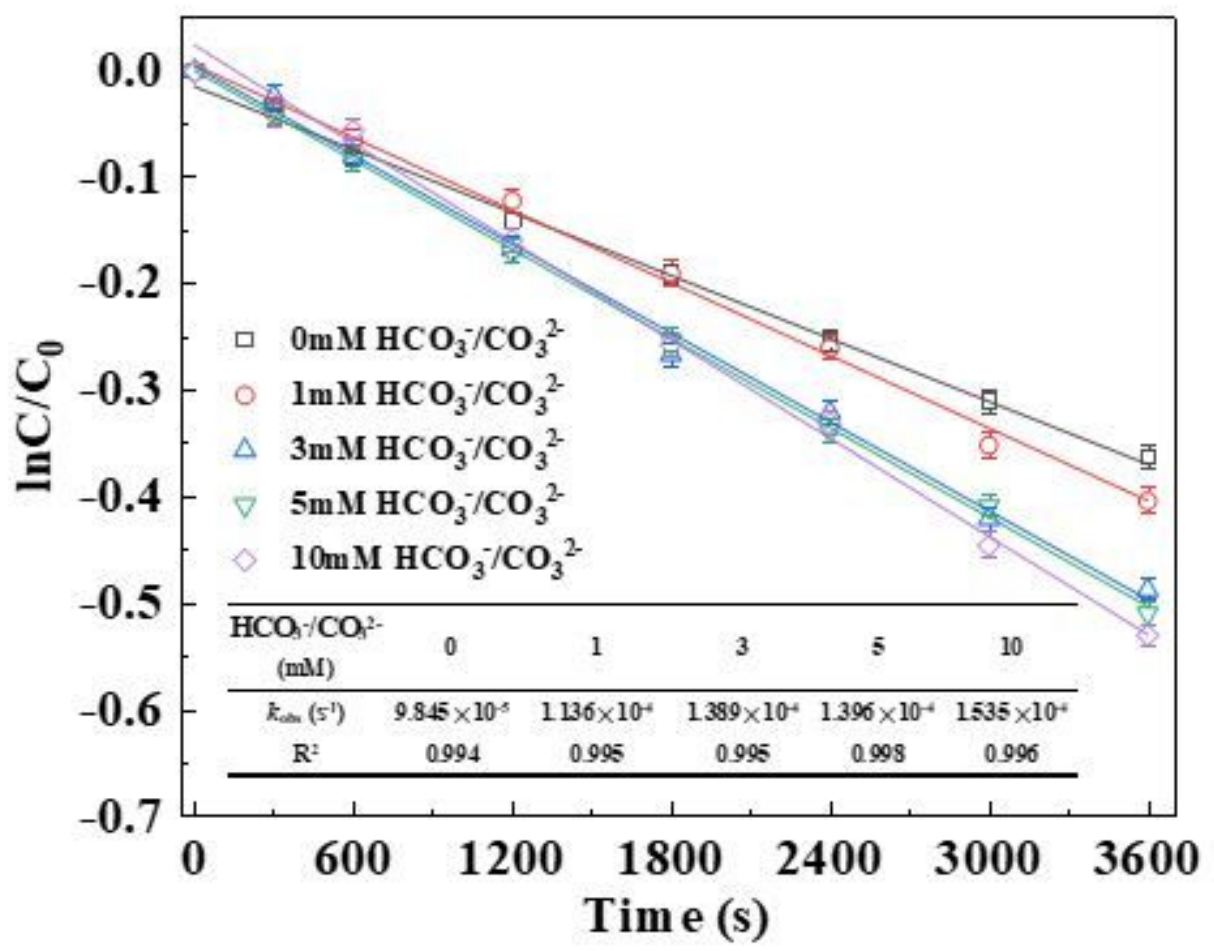


Figure 8

Effect of HCO3-/CO32- on BPA degradation in UV/nitrate process. Experimental conditions:[BPA] = $30 \mu \mathrm{M}$, [NO3-] $=30 \mathrm{mM}, \mathrm{pH}=7$, [phosphate] $=5 \mathrm{mM}$, time $=3600 \mathrm{~s}, \mathrm{I}=0.172 \mathrm{~mW} \cdot \mathrm{cm}-2$.

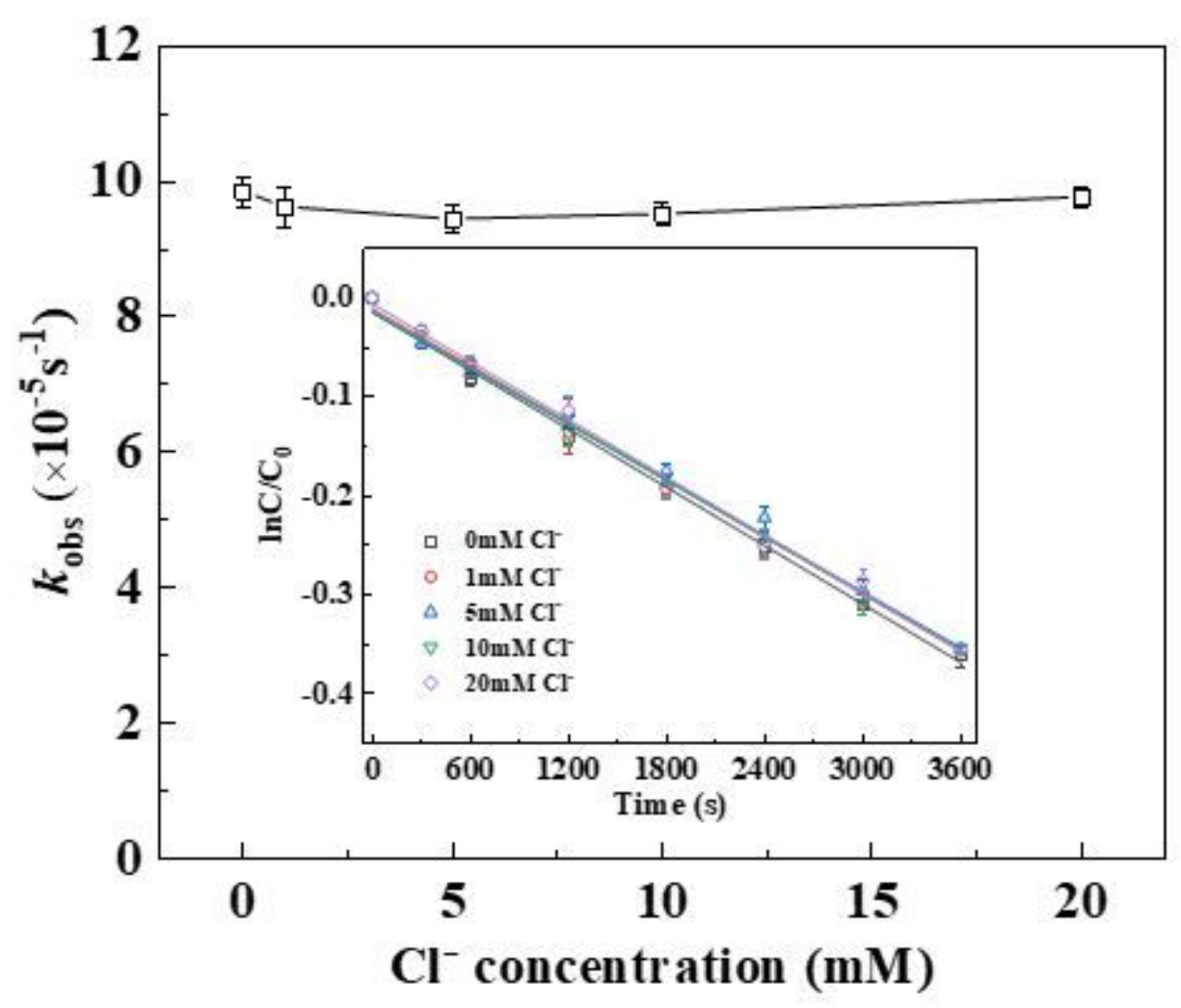

Figure 9

The changes of kobs with $\mathrm{Cl}$ - concentration in UV/nitrate process. Experimental conditions:[BPA] = $30 \mu \mathrm{M}$, [NO3] $=30 \mathrm{mM}, \mathrm{pH}=7$, [phosphate] $=5 \mathrm{mM}$, time $=3600 \mathrm{~s}, \mathrm{I}=0.172 \mathrm{~mW} \cdot \mathrm{cm}-2$. 


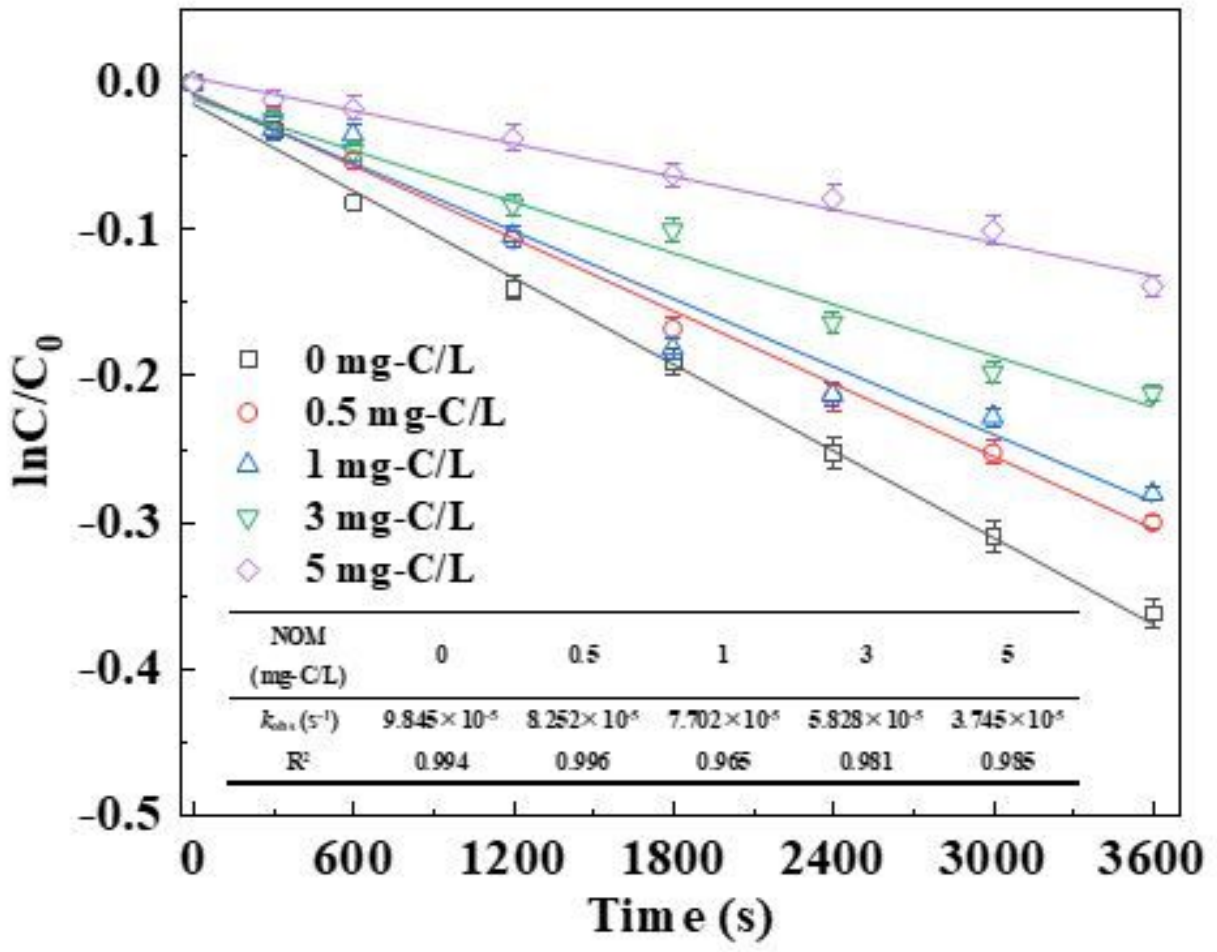

Figure 10

Effect of NOM on BPA degradation. Experimental conditions:[BPA] $=30 \mu \mathrm{M}$, [NO3-] $=30 \mathrm{mM}, \mathrm{pH}=7$, [phosphate] $=5 \mathrm{mM}$, time $=3600 \mathrm{~s}, \mathrm{I}=0.172 \mathrm{~mW} \cdot \mathrm{cm}-2$. 


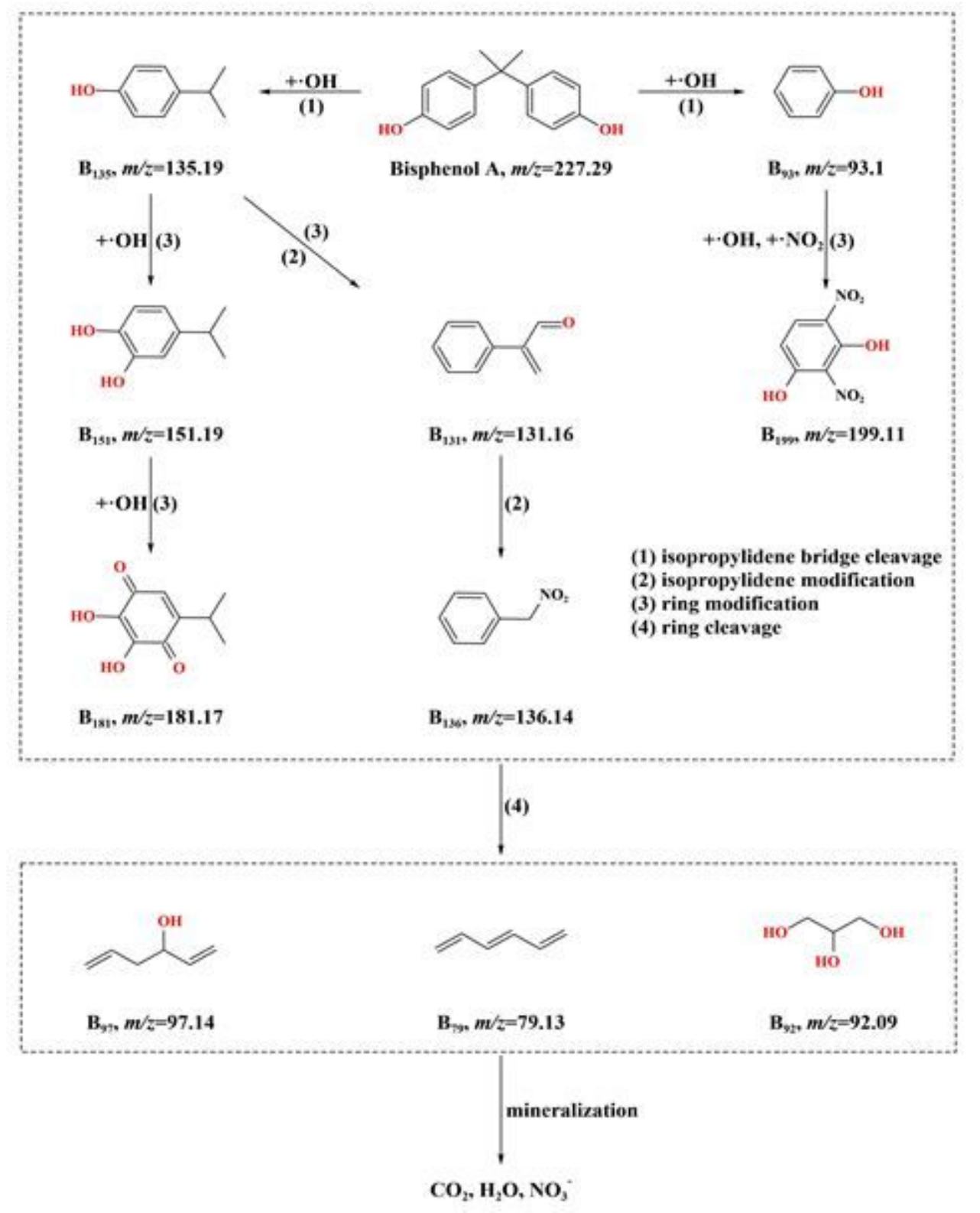

Figure 11

Proposed transformation pathways of BPA in UV/nitrate process. Experimental conditions:[BPA] $=30 \mu \mathrm{M}$, [NO3-] $=30 \mathrm{mM}, \mathrm{pH}=7$, [phosphate] $=5 \mathrm{mM}$, time $=7200 \mathrm{~s}, \mathrm{I}=0.172 \mathrm{~mW} \cdot \mathrm{cm}-2$. 


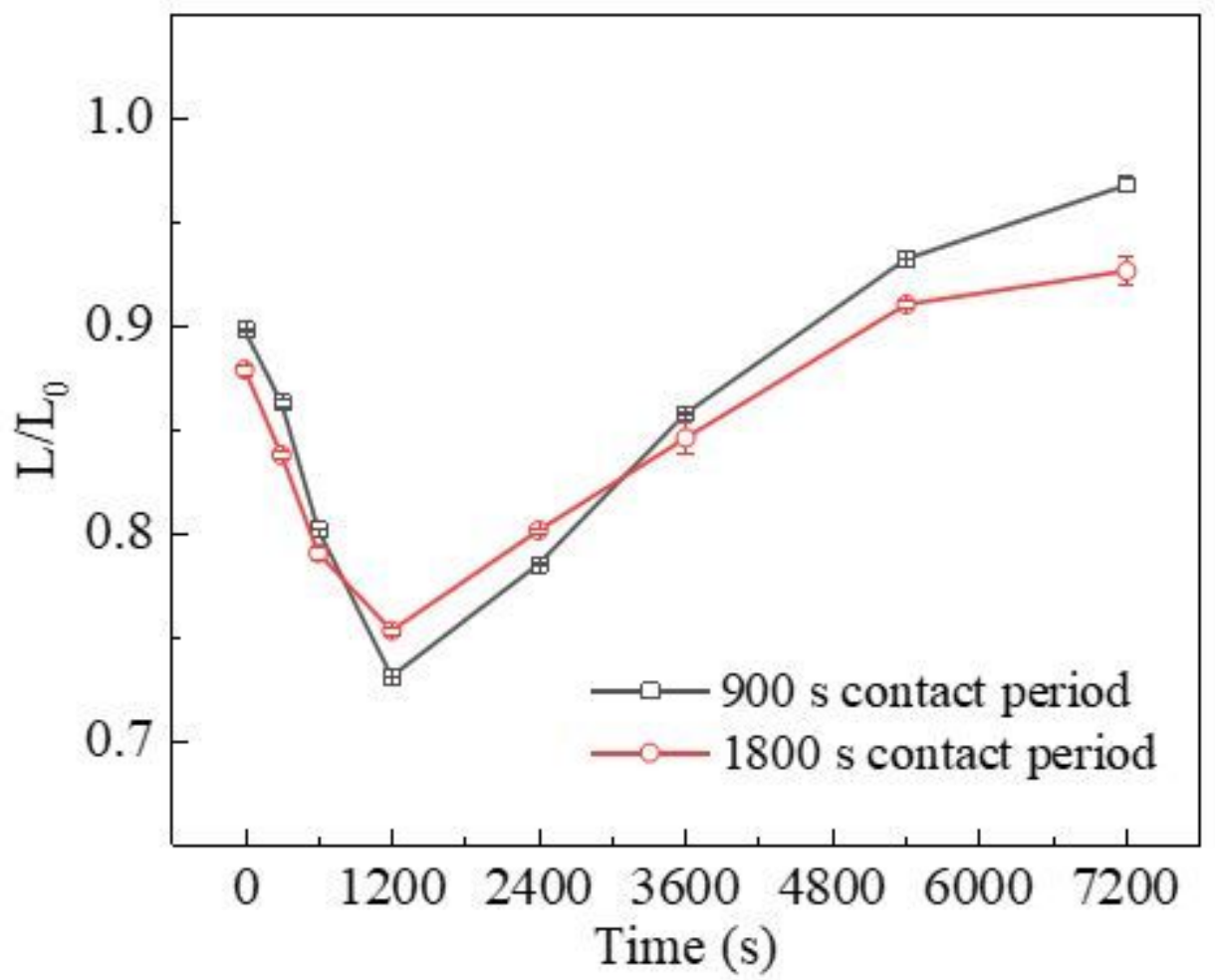

Figure 12

Variation of bioluminescence of Vibrio fischeri during BPA degradation by UV/nitrate process.

Experimental conditions:[BPA] $=1 \mu \mathrm{M},[\mathrm{NO3}-]=30 \mathrm{mM}, \mathrm{pH}=7$, [phosphate] $=5 \mathrm{mM}$, time $=7200 \mathrm{~s}, \mathrm{I}=$ $0.172 \mathrm{~mW} \cdot \mathrm{cm}-2$.

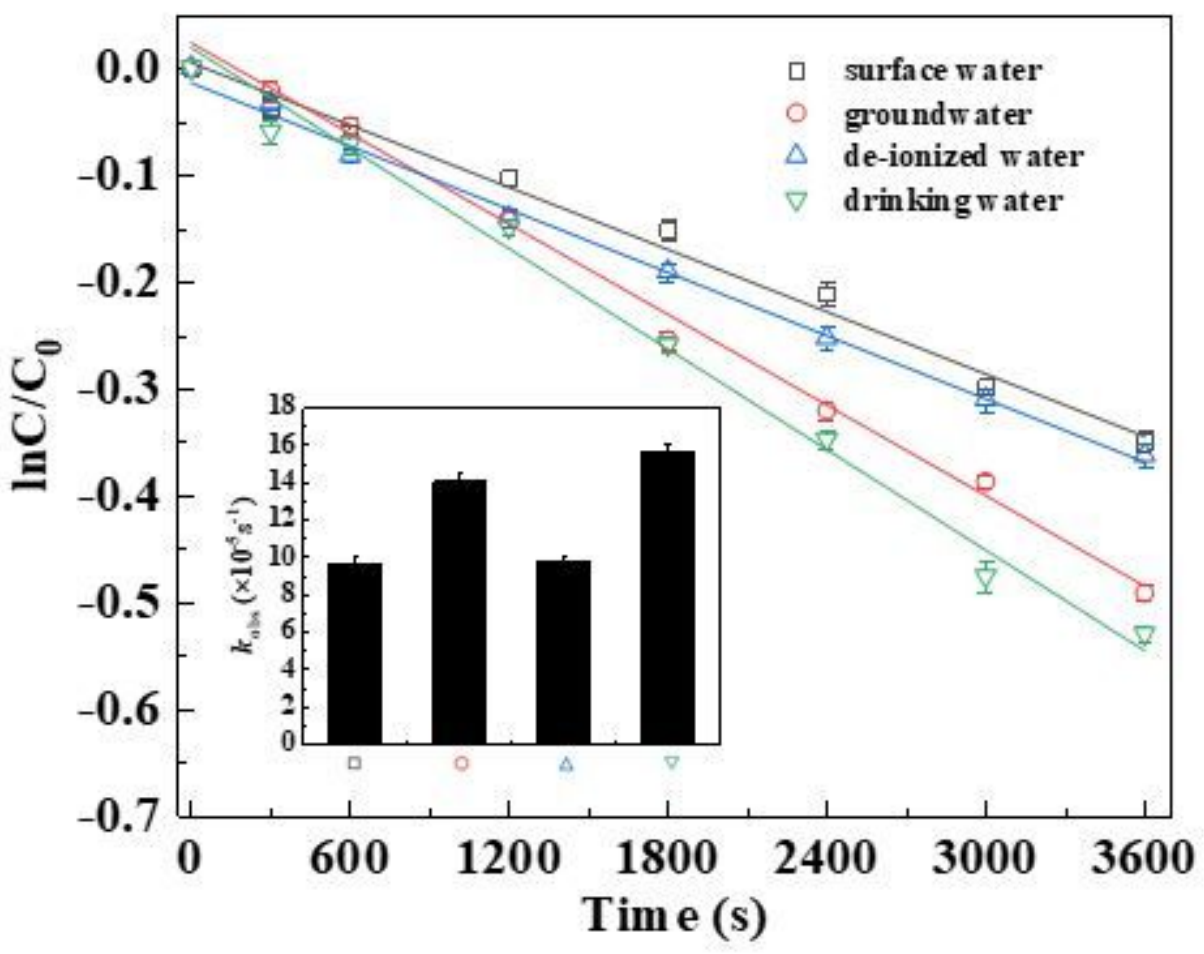


Figure 13

Effect of actual waters components on BPA degradation in the UV/nitrate process. Experimental conditions:[BPA] $=30 \mu \mathrm{M},[\mathrm{NO3}]=30 \mathrm{mM}, \mathrm{pH}=7$, [boric acid buffer] $=5 \mathrm{mM}$, time $=3600 \mathrm{~s}, \mathrm{I}=0.172$ $\mathrm{mW} \cdot \mathrm{cm}-2$.

\section{Supplementary Files}

This is a list of supplementary files associated with this preprint. Click to download.

- Supplementaryinformation.docx 